$$
\text { UNIVERSIDADE dE SÃo PAULO }
$$

Faculdade de Medicina de Ribeirão Preto PÓS-GRADUAÇÃo EM IMUNOLOGIA BÁSICA E APLICADA

\title{
Papel dos Monócitos Inflamatórios na Sepse
}

Guilherme Cesar Martelossi Cebinelli

\author{
RibeiRÃo PRETO
}


UNIVERSIDADE DE SÃo PAULO

Faculdade de Medicina de Ribeirão Preto

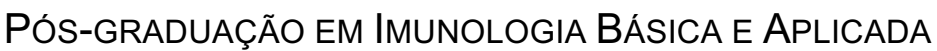

PAPEL dOS MONÓCITOS INFLAMATÓRIOS NA SEPSE

Guilherme Cesar Martelossi Cebinelli

DISSERTAÇÃO APRESENTADA AO PROGRAMA DE PÓS-GRADUAÇÃO

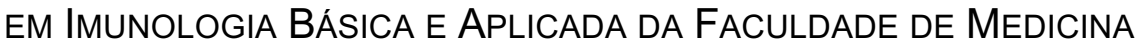
de Ribeirão Preto da Universidade de São Paulo para obtenção do título de Mestre em ClênCias, na Área de CONCENTRAÇÃO: IMUNOLOGIA BÁSICA E APLICADA.

Orientador: Prof. Dr. Fernando de QueIroz CunHa

RIBEIRÃo PRETO

2018 
AUTORIZO A REPRODUÇÃO E DIVULGAÇÃO TOTAL OU PARCIAL DESTE TRABALHO, POR QUALQUER MEIO CONVENCIONAL OU ELETRÔNICO, PARA FINS DE ESTUDO E PESQUISA, DESDE QUE CITADA A FONTE.

Cebinelli, Guilherme Cesar Martelossi

Papel dos monócitos inflamatórios na sepse, 2018.

$67 \mathrm{p}$.

Dissertação apresentada ao programa de pós-graduação em Imunologia Básica e Aplicada da Faculdade de Medicina de Ribeirão Preto da Universidade de São Paulo para obtenção do título de Mestre em Ciências, na área de concentração: Imunologia Básica e Aplicada.

Orientador: Prof. Dr. Fernando de Queiroz Cunha.

1. Sepse. 2. Monócitos inflamatórios. 3. Lesão de órgãos. 
Guilherme Cesar Martelossi Cebinelli

PAPEL DE MONÓcitos INFLAMATÓRIOS NA SEPSE

DISSERTAÇÃO APRESENTADA AO PROGRAMA DE PÓS-GRADUAÇÃO EM ImUnologia BÁsica e Aplicada da Faculdade de Medicina de Ribeirão Preto da Universidade de SÃo Paulo para obtenção do título de MEstre em CiênCIAS, NA ÁREA dE CONCENTRAÇÃo: IMUNOLOGIA BÁSICA E APLICADA.

APROVADO EM: DE DE

\section{BANCA EXAMINADORA}

Prof. Dr. FERnANDO de QueIROZ CUNHA

Faculdade de Medicina de Ribeirão Preto

PROF. DR. JoÃo SANTANA dA SILVA

FACUldade de Medicina de Ribeirão PREto

Profa. DRA. LARISSA Dias dA CUNHA

Faculdade de Medicina de Ribeirão Preto

Prof. Dr. MARCELo TORRES BozZA

UNIVERSIDADE FEDERAL dO RIO DE JANEIRO 


\section{AgRAdeCIMENTOS}

Agradeço ao Professor Dr. Fernando de Queiroz Cunha, profissional e pessoa exemplar, pela orientação, pelos valiosos ensinamentos que contribuíram para o meu crescimento científico, intelectual e pessoal.

Aos demais Professores do Laboratório de Inflamação e Dor, Prof. Dr. Thiago Mattar Cunha, e Prof. Dr. José Carlos Alves Filho, pelas contribuições científicas e ensinamentos que contribuíram para o meu crescimento científico.

Agradeço aos Professores, Dr. Marcelo Torres Bozza; Dra. Larissa Dias da Cunha; e Dr. João Santana da Silva, pela disponibilidade de participar desta banca examinadora, que será de grande valia para as discussões e aperfeiçoamento deste trabalho.

Aos meus pais Júlio Cesar Cebinelli e Gislaine Maria Martelossi Cebinelli, e a minha irmã Geovana Martelossi Cebinelli, pelo amor e carinho incondicional, pelos ensinamentos e exemplos os quais me definiram. Obrigado por estarem presentes nos momentos difíceis, me ajudando; e nos felizes, celebrando. Agradeço toda minha família, em especial minha vó, Darcy Furlan Martelossi, quem muito me incentivou e contribuiu com a minha educação.

Aos colegas do Laboratório de Inflamação e Dor, um laboratório fenomenal e fascinante, pois sempre obtive apoio científico e metodológico quando precisei. Agradeço pelas discussões científicas sobre esse trabalho, momentos de diálogo e aprendizado, e também pelos momentos de descontração (obs: fiquei com medo de escrever o nome de todos e esquecer de alguém, seria uma injustiça).

Aos técnicos Serginho, Diva, leda e Marquinhos, pela amizade, suporte técnico, carinho e disponibilidade. Minha imensa admiração por manterem organizado um laboratório desse porte. Em especial, agradeço a rainha das 
compras, Katinha, pelo carinho comigo durante esses anos, obrigado pelo Whey. Ainda, à Denise, pelo apoio nas longas separações de células na facility de citometria da FMRP, e pelos treinamentos operacionais. À Ana Cristine, pelo auxílio burocrático, obrigado.

Obrigado aos meus amigos mais próximos, que diretamente ou indiretamente participaram desse trabalho e da minha formação, lá vai ... Kalil WILLIAM Alves de Lima (criatura), Fernanda Vargas da Silva Castanheira (FêFer), e Paula Barbim Donate Yabuta (criatura) pessoas chave na minha formação pessoal e acadêmica (Pai, Tia e Mãe científicos, Fernando é o vô). Carlos Hiroji Hiroki e Amanda Cristina (Cris) Corveloni, minha First Family aqui em Ribeirão Preto, obrigado por esses 6 anos de amizade, desde a época da graduação. Obrigado, Bruno Marcel, Rafaela MANO (cuidado) Guimarães (marca de bolsa), Timna Varela (Tina), Marcos Rosa (Marcão), Mikhael Haruo (Mikha), Eduardo Damasceno, Marcela Davoli, Daniele Nascimento (Dani), Flávio Protássio (Prots), Thainá Norbinato (portãozinho), Cleyson Oliveira e Leonardo Lima, não é fácil me aguentar, eu acho, parabéns! Agradeço pelos momentos de trabalho e de diversão.

Às agências de fomento, Coordenação de Aperfeiçoamento Pessoal de Nível Superior (CAPES), Conselho Nacional de Desenvolvimento Tecnológico e Científico (CNPQ), Fundação de Amparo à Pesquisa do Estado de São Paulo (FAPESP) e ao Centerfor Research in Inflammatory Diseases (CRID) pelo apoio financeiro fundamental para desenvolvimento deste trabalho e concessão de bolsa de estudo $(\mathrm{CNPq})$

E a todos, que direta ou indiretamente, contribuíram para meu crescimento pessoal e profissional e para a realização deste trabalho.

O meu muito obrigado! 
"EM ALGUM LUGAR, ALGUMA COISA INCRÍVEL ESTÁ ESPERANDO PARA SER DESCRITA"

(CARL SAgAN) 


\section{RESUMO}

Cebinelli, Guilherme Cesar Martelossi. Papel de monócitos inflamatórios na sepse. 2018. 67f. Dissertação (Mestrado em Imunologia Básica e Aplicada) Faculdade de Medicina de Ribeirão Preto, Universidade de São Paulo, Ribeirão Preto, 2018.

Sepse é uma síndrome, na qual, o paciente apresenta lesões de órgãos com risco a vida, em decorrência de uma inflamação exagerada desencadeada por uma infecção. Estima-se uma ocorrência anual de 31,5 milhões de casos de sepse e 19,4 milhões de casos de choque séptico no mundo, causando potencialmente 5,3 milhões de mortes. Esses índices alarmantes fizeram com que em 2017, a Organização Mundial da Saúde (OMS) adotasse uma resolução com o objetivo de aperfeiçoar a prevenção, diagnóstico e tratamento dessa condição clínica que vem sendo negligenciada. A iniciação da sepse, ocorre quando há um descontrole da infecção, acarretando excessiva ativação de células do sistema imune inato. Isso resulta em uma inflamação sistêmica danosa que é responsável pela maioria das alterações fisiopatológicas da sepse. Nesse contexto do sistema imune inato, o papel de neutrófilos já é bem compreendido da patogênese da sepse. Contudo, a função dos monócitos inflamatórios ainda não é bem estabelecida. Ao mesmo tempo que essas células podem participar do controle de infecções, elas também podem contribuir com a inflamação sistêmica e a lesão de órgãos. Deste modo, a compreensão do papel dessas células se faz importante para determinação de novos alvos terapêuticos para essa condição clínica. Nossos resultados demonstraram, em modelo experimental de sepse, que o aumento da emigração de monócitos inflamatórios da medula óssea está relacionado com maior taxa de mortalidade dos animais e exacerbação da inflamação sistêmica. A migração dessas células para órgãos, como rim e pulmão, está relacionado com inflamação e aumento de lesões, nesses locais. Deste modo, conclui-se que monócitos inflamatórios possuem um papel deletério na patogênese da sepse.

Palavras chave: Monócitos inflamatórios, exacerbação da inflamação, sepse. 


\begin{abstract}
Cebinelli, Guilherme Cesar Martelossi. The role of inflammatory monocytes in sepsis. 2018. 67f. Dissertation (Mestrado em Imunologia Básica e Aplicada) Faculdade de Medicina de Ribeirão Preto, Universidade de São Paulo, Ribeirão Preto, 2018.

Sepsis is a syndrome in which the patient has life-threatening organ damage due to an exaggerated inflammation triggered by an infection. The annual occurrence is 31.5 million cases of sepsis and 19.4 million cases of septic shock in the world, which potentially cause 5.3 million deaths. In concern of these alarming reports in 2017, the World Health Organization (WHO) adopted a resolution aimed at improving the prevention, diagnosis and treatment of this neglected clinical condition. The initiation of sepsis occurs when the infection was not controlled, causing excessive activation of the innate immune cells. This excessive activation causes a systemic inflammation that is responsible for most pathophysiological phenomena in sepsis. In this context of the innate immune system, the role of neutrophils is already well understood in the pathogenesis of sepsis. However, the role of inflammatory monocytes is not yet well established. These cells can participate in the control of infections, or can also contribute to systemic inflammation and organs damage. Thus, the understanding of the roles of these cells become important for the development of new therapeutic targets for this clinical condition. Our results demonstrated that the systemic increase of the inflammatory monocytes frequency is related to higher mortality rate, exacerbation of systemic inflammation, increased migration to organs (lung and kidney), and in these sites, are related to inflammation and lesions. Thus, we concluded that these cells have a deleterious role in the pathogenesis of sepsis.
\end{abstract}

Keywords: Inflammatory monocytes, exacerbated inflammation, sepsis. 
LISTA DE FIGURAS

FIGURA 1: ESTRATÉGIA DE GATES DE CITOMETRIA. 32

FIgURA 2: ANIMAIS SUBMETIDOS A SEPSE LETAL APRESENTAM FALÊNCIA NA MIGRAÇÃO DE MONÓCITOS INFLAMATÓRIOS E NEUTRÓFILOS PARA O FOCO INFECCIOSO. 38

FIgURA 3: ANIMAIS SUBMETIDOS A SEPSE GRAVE APRESENTAM MAIOR INFILTRADO DE MONÓCITOS INFLAMATÓRIOS E NEUTRÓFILOS NO PULMÃO. 40

Figura 4: ANIMAIS deficientes PARA CCR2 APRESENTAM MENOR EMIGRAÇÃo de MONÓCITOS INFLAMATÓRIOS DA MEDULA ÓSSEA, PORÉM A EMIGRAÇÃO DE NEUTRÓFILOS É SEMELHANTE AOS ANIMAIS WT.

FIguRA 5: ANIMAIS DEFICIENTES PARA CCR2 APRESENTAM MENOR MIGRAÇÃo DE MONÓCITOS INFLAMATÓRIOS PARA A CAVIDADE PERITONEAL. 43

FIgURA 6: ANIMAIS DEFICIENTES PARA CCR2 APRESENTAM MAIOR MIGRAÇÃO DE NEUTRÓFILOS PARA A CAVIDADE PERITONEAL. 43

FIGURA 7: ANIMAIS DEFICIENTES PARA CCR2 E WT NÃO POSSUEM DIFERENÇA NOS NÍVEIS DE CITOCINAS E QUIMIOCINAS NO FOCO INFLAMATÓRIO QUANDO SUBMETIDOS À SEPSE MODERADA.

Figura 8: ANIMAIS DEFICIENTES PARA CCR2 APRESENTAM MAIOR SOBREVIDA A SEPSE, PORÉM SIMILAR CARGA BACTERIANA NO SANGUE E FOCO INFECCIOSO.

FIgURA 9: MONÓCITOS INFLAMATÓRIOS POSSUEM ATIVIDADE MICROBICIDA E PRODUZEM ÓXIDO NÍTRICO.

FIgURA 9: ANIMAIS DEFICIENTES PARA CCR2 APRESENTAM MENORES NÍVEIS SISTÊMICOS DE CXCL2, IL-6 E IL-10, E SIMILARES NÍVEIS DE CCL2 EM RELAÇÃO AOS ANIMAIS WT... 47

Figura 10: ANimAis deficientes PARA CCR2 APRESENTAM MENOR INFILTRAdO DE MONÓCITOS INFLAMATÓRIOS NO PULMÃO E RIM, PORÉM MESMO INFILTRADO DE NEUTRÓFILOS. 
Figura 11: ANIMAIS DEFICIENTES PARA CCR2 APRESENTAM MENORES NíVEIS DE

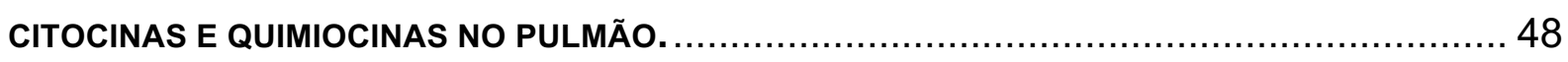

FIgURA 12: ANIMAIS DEFICIENTES PARA CCR2 APRESENTAM MENORES NÍVEIS DE IL-6 NO RIM.

FIgURA 13: ANIMAIS DEFICIENTES PARA CCR2 APRESENTAM MENORES NÍVEIS DE MARCADORES DE LESÃO DE ÓRGÃOS: TGO E CK-MB. 49

FIgURA 14: A TRANSFERÊNCIA DE MONÓCITOS INFLAMATÓRIOS PARA ANIMAIS AUMENTA A SUSCETIBILIDADE A SEPSE DE ANIMAIS DEFICIENTES PARA CCR2. 50 
SUMÁRIO

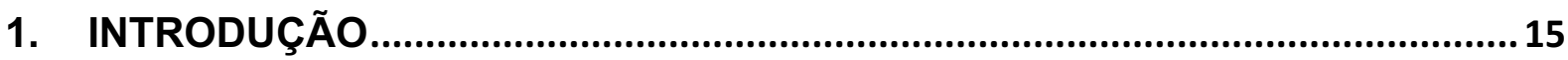

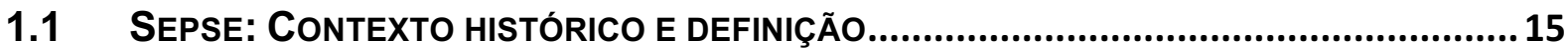

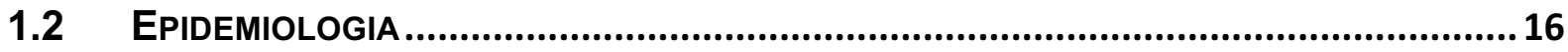

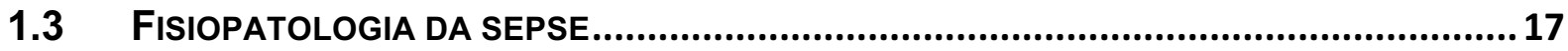

1.3.1 RECONHECIMENTO DO PATÓGENO ............................................................. 18

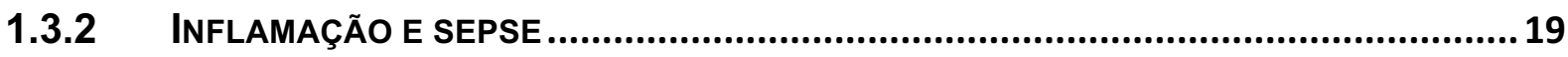

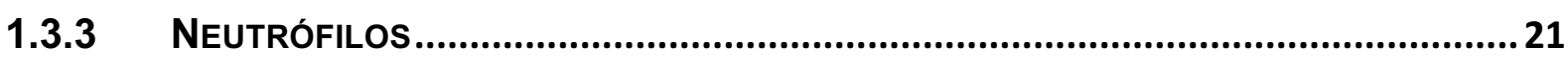

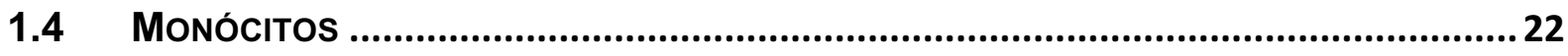

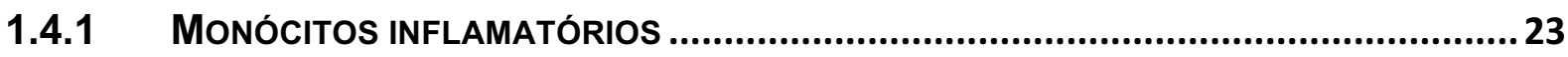

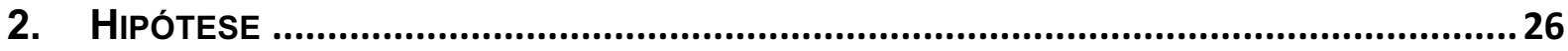

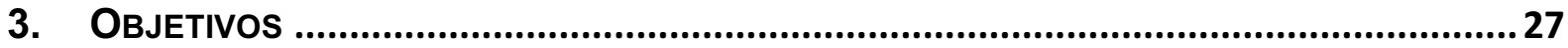

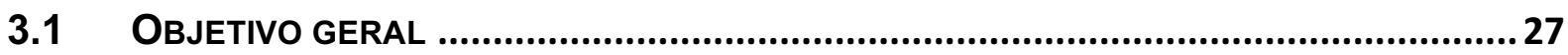

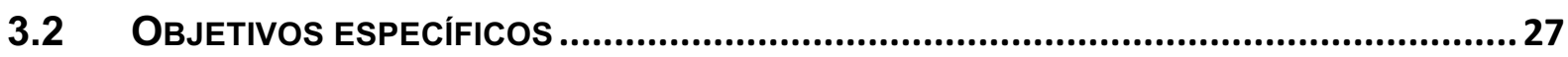

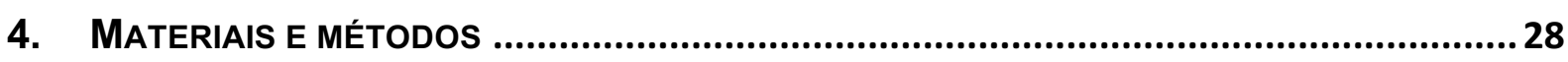

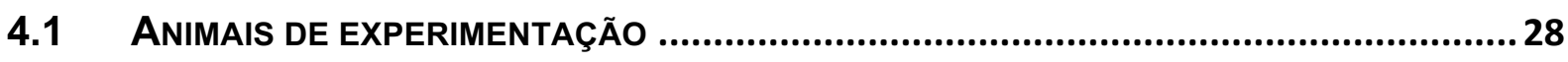

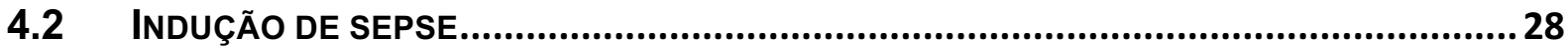

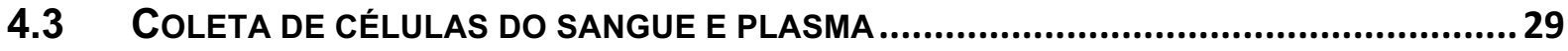

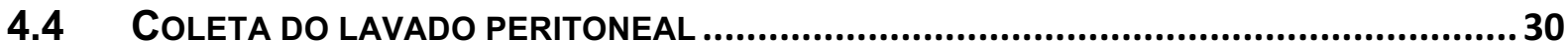

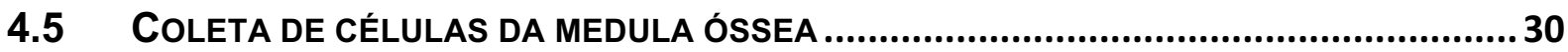

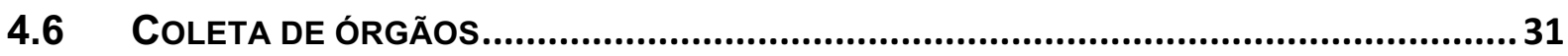

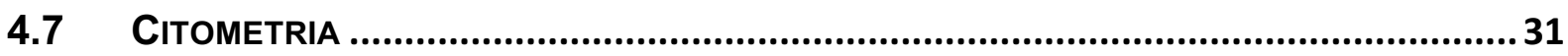

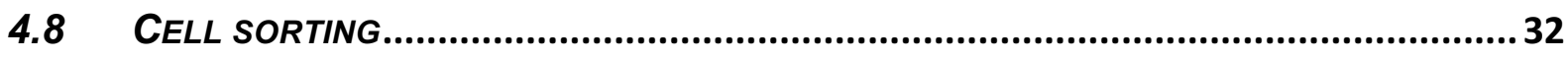

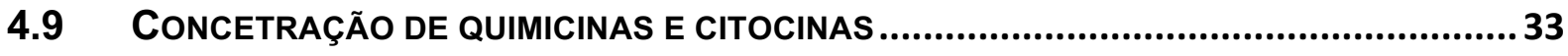

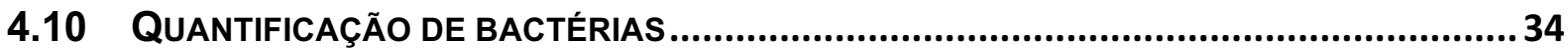

4.11 ATIVIDADE MICROBICIDA E QUANTIFICAÇÃO DE NITRITO ......................................35

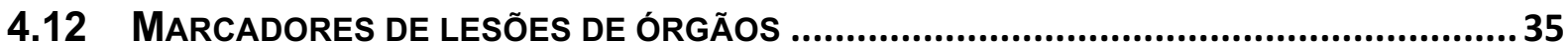

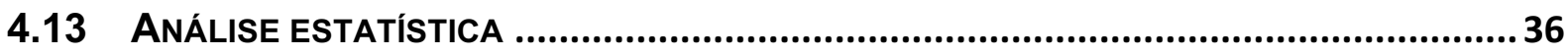

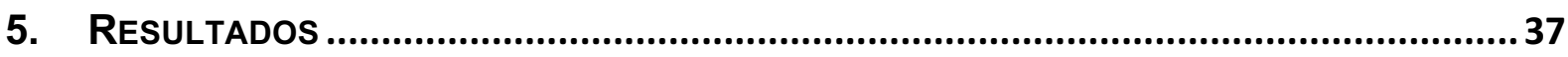

5.1 ANIMAIS COM SEPSE GRAVE APRESENTAM FALÊNCIA NA MIGRAÇÃO DE MONÓCITOS

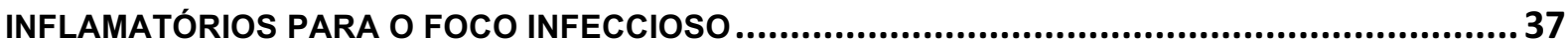

5.2 ANIMAIS COM SEPSE GRAVE APRESENTAM MAIOR INFILTRADO DE MONÓCITOS

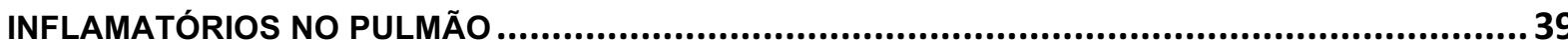


5.3 ANIMAIS CCR2 ${ }^{-/-}$APRESENTAM DEFICIÊNCIA NA EMIGRAÇÃO DE MONÓCITOS INFLAMATÓRIOS DA MEDULA ÓSSEA E MENOR FREQUÊNCIA DESSAS CÉLULAS NO LOCAL DA INFECÇÃO

5.4 ANIMAIS DEFICIENTES PARA CCR2 APRESENTAM MAIOR SOBREVIDA EM RELAÇÃO AOS ANIMAIS WT, PORÉM NÃO APRESENTAM DIFERENÇA NA CARGA BACTERIANA E NÍVEIS DE CITOCINAS E QUIMIOCINAS NO FOCO INFLAMATÓRIO

5.5 ANIMAIS DEFICIENTES PARA CCR2 APRESENTAM MENORES NÍVEIS DE CXCL2, IL-6 E IL-10 NO PLASMA, ASSIM COMO MENOR PRODUÇÃO DESSAS CITOCINAS E MENOR INFILTRADO DE MONÓCITOS INFLAMATÓRIOS NOS PULMÕES E RINS.. .46

5.6 ANIMAIS DEFICIENTES PARA CCR2 QUE RECEBERAM MONÓCITOS INFLAMATÓRIOS

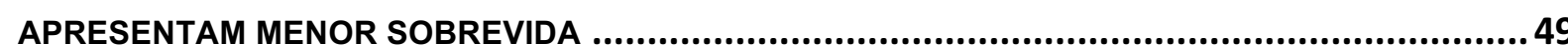

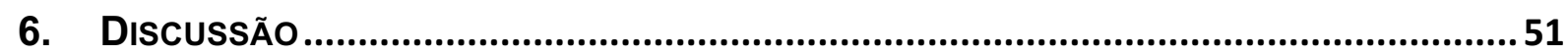

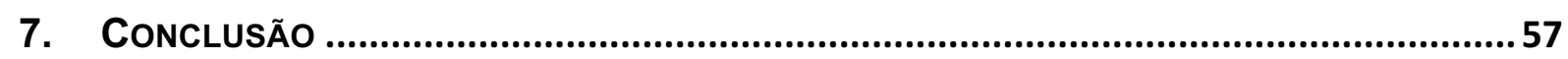

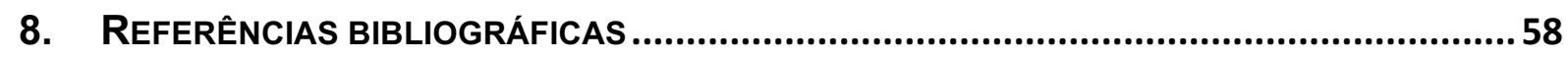

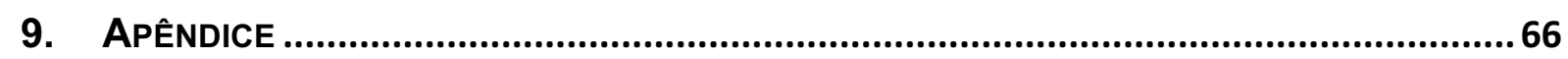




\section{INTRODUÇÃO}

\subsection{Sepse: ConteXto históRico e definição}

Por definição, a sepse é uma síndrome, na qual, o paciente apresenta lesões de órgãos com risco a vida, em decorrência de uma inflamação exagerada desencadeada por uma infecção. Já o choque séptico, ocorre quando o paciente necessita de vasopressores para manutenção da pressão arterial, quadro em que pacientes apresentam mais risco de morte (SINGER et al., 2016).

A primeira descrição da manifestação de sepse foi feita por Hipócrates, como putrefação do sangue e tecidos (460-377 antes de cristo). No entanto, o uso do termo sepse, no contexto médico, é datado de mais de 2700 anos atrás nos poemas de Homero (FUNK; PARRILLO; KUMAR, 2009). Posteriormente, por volta dos anos 1000, o Islamita Ibn Sīnā (980-1037), considerado o pai da medicina moderna, observou que o quadro de sepse ocorria comumente com a presença de febre. Com a confirmação da teoria dos germes por Semmelweis, Pasteur e outros, descreveram que a sepse é causada por uma infecção que se espalha para a corrente sanguínea, acarretando uma inflamação sistêmica (FUNK; PARRILLO; KUMAR, 2009; HOTCHKISS et al., 2016). Contudo, com o advento de antibióticos modernos, muitos pacientes continuaram a morrer de sepse mesmo com a completa erradicação da infecção. Deste modo, pesquisas nesta área sugeriram que a resposta do hospedeiro, e não apenas os microrganismos, era o principal fator relacionado com a patogênese da sepse. (ANGUS; VAN DER POLL, 2013; CERRA, 1985). 
Contudo, somente em 1991 foi realizado o primeiro consenso para a definição dessa condição clínica, a qual foi sendo subsequentemente redefinida. A definição atual é fruto do último consenso que ocorreu em 2016 (SINGER et al., 2016). Além disso, outras definições e padronizações foram reforçadas. Uma delas foram os critérios utilizados para identificar pacientes com sepse, determinar o grau dessa condição, e indicar a melhor terapia a ser adotada. Essa padronização é denominada SOFA (Sequencial Organ Failure Assessment, ou originalmente: Sepsis-related Organ Failure Assessment (VINCENT et al., 1998).

O SOFA é calculado pelos scores atribuídos aos pacientes de acordo com: a taxa respiratória (medida pela razão da pressão de oxigênio no sangue arterial com a fração inspirada de oxigênio), coagulação sanguínea (medida pelo número de plaquetas circulantes) e pressão arterial média, dano hepático (medido pelos níveis de bilirrubina no sangue), dano renal (medido pelos níveis de creatinina circulantes) e o dano no sistema nervoso central (medido pela escala de coma de Glasgow). Com isso, o cálculo do SOFA define o grau de sepse que o paciente possui, e auxilia no tipo de tratamento a ser adotado (VINCENT et al., 1998). Pacientes são diagnosticados com sepse quando apresentam suspeita ou confirmação de infecção associada a um score SOFA igual ou maior que 2 (SINGER et al., 2016).

\subsection{EpIDEMIOLOGIA}

Apesar dos avanços na compreensão da fisiopatologia da sepse, a sua incidência cresce exponencialmente, (MARTIN et al., 2003). Estima-se uma ocorrência anual de 31,5 milhões de casos de sepse e 19,4 milhões de casos de 
choque séptico no mundo, causando potencialmente 5,3 milhões de mortes, índice maior que a soma de mortes caudadas pelo câncer de pulmão, mama e cólon (FLEISCHMANN et al., 2016). No Brasil, $30,2 \%$ dos pacientes internados em Unidades de Terapia Intensiva (UTI) apresentam sepse e o custo médio por paciente é de aproximadamente dois mil reais/dia (MACHADO et al., 2017; SOGAYAR et al., 2008). A incidência anual dessa condição é estimada em aproximadamente 420 mil casos, dos quais 230 mil pacientes morrem (MACHADO et al., 2017). Apesar desses dados alarmantes, a sepse se mantém como uma condição negligenciada, sendo geralmente desconhecida pela população em geral (REINHART et al., 2017).

Visto o elevado índice de mortalidade associado ao quadro de sepse, em maio de 2017, a Organização Mundial da Saúde (OMS) adotou uma resolução com o objetivo de aperfeiçoar a prevenção, diagnóstico e tratamento dessa condição clínica (REINHART et al., 2017). Deste modo, além de campanhas de educação para a população, existe necessidade do desenvolvimento de novas abordagens terapêuticas que sejam mais eficientes e que, por conseguinte, levem à redução da alta taxa de mortalidade.

\subsection{FISIOPATOLOGIA DA SEPSE}

$\mathrm{Na}$ maioria dos casos, a ativação da resposta imune inata, através do reconhecimento do patógeno é capaz de controlar a infecção. No entanto, em alguns casos, a presença do patógeno prevalece e a resposta do hospedeiro pode se tornar descontrolada, resultando em uma inflamação sistêmica e comprometimento de órgãos (HOTCHKISS et al., 2016). A ineficiência na eliminação do patógeno pode 
ser o resultado, por exemplo, da presença de superantígenos, microrganismos resistentes a opsonização, a fagocitose ou a terapia com antibióticos (STEARNSKUROSAWA et al., 2011). Além disso, fatores de risco relacionados com o hospedeiro aumentam as chances do aparecimento de sepse. Esses fatores na maioria das vezes estão relacionados com algum comprometimento do sistema imunológico, como idosos, portadores de doenças crônicas (síndrome da imunodeficiência adquirida, doença pulmonar obstrutiva crônica, e câncer), ou usuários de agentes imunossupressores, e crianças cujo sistema imunológico ainda está em maturação (ANGUS et al., 2001).

A sepse é resultante de infecções adquiridas no contexto hospitalar ou fora dele. Dentre as infecções, a pneumonia é o tipo mais comum, seguida de infecções intra-abdominais e do trato urinário. Staphylococcus aureus e Streptococcus pneumonia são as gram-positivas mais comumente isoladas e Escherichia coli, Klebsiella sp., e Pseudomonas aeruginosa predominam entre as gram-negativas (OPAL et al., 2003; RANIERI et al., 2012). Dependendo da causa da sepse, mais de um patógeno pode ser identificado, porém a maior parte das infecções é causada por bactérias gram-positivas (47\%) e gram-negativas (62\%), mas cerca de $20 \%$ dos pacientes também apresentam infecções por fungos (VINCENT et al., 2009). No entanto, sepse também pode ser causada por infecções virais, como o vírus da dengue (HOTCHKISS et al., 2016).

\subsubsection{RECONHECIMENTO dO PATÓgENO}

Os mecanismos de defesa iniciam-se com o reconhecimento do microrganismo invasor. Este reconhecimento ocorre por meio de estruturas 
conservadas, constitutivamente expressas em sua superfície, denominadas de padrões moleculares associados a patógenos (PAMPs, pathogen-associated molecular patterns) (MEDZHITOV, 2007). Os PAMPs são reconhecidos por receptores encontrados em células do sistema imune inato, entre elas macrófagos, neutrófilos e células dendríticas. Esses receptores são coletivamente denominados de receptores de reconhecimento de padrões (PRRs, pattern recognition receptors). Entre os membros mais importantes dos PRRs destacam-se os receptores do tipo Toll (TLRs, Toll-like receptors), que são capazes de reconhecer lipopolissacarídeo (LPS) de gram-negativas, o ácido lipoteicóico (LTA) e peptideoglicanas (PGN) de gram-positivas, bem como componentes da parece celular de fungos e ácidos nucleicos virais, entre outros (ALVES-FILHO et al., 2006, 2008; MEDZHITOV; JANEWAY, 2000).

\subsubsection{INFLAMAÇÃo E SEPSE}

Após o reconhecimento do patógeno pelos PRRs, complexas vias de transdução de sinal são iniciadas, as quais culminam na fosforilação e ativação de proteínas kinase ativada por mitógeno (MAPKs), Janus kinases (JAKs), STATs (signal transducers and activators of transcription), ou a translocação nuclear do fator nuclear kB (NF-kB). Como resultado são expressos vários genes, entre eles os de citocinas associadas com a inflamação incluindo o fator de necrose tumoral (TNF), Interleucina 1 (IL-1), IL-12, IL-18 e Interferons do tipo 1 (IFNs). Esses mediadores levam a produção e liberação de outras citocinas pró-inflamatórias e quimiocinas (incluindo, IL-6, IFN gama, quimiocina ligante CC 2 (CCL2), CCL3, e 
quimiocina ligante CXC 1, 2 e 10 (CXCL1, CXCL2 e CXCL10) (HOTCHKISS et al., 2016).

A liberação de citocinas e quimiocinas por células residentes, presentes no local da infecção, tem um papel importante no recrutamento de leucócitos ao foco inflamatório, resultante da síntese de moléculas de adesão na superfície, formação de gradiente quimiotático e ativação desses leucócitos (KUBES, 2002), que resulta em eliminação do patógeno.

Durante a sepse, há um descontrole da infecção, acarretando excessiva presença de PAMPs. Desse modo, a excessiva ativação, via PRRs, de células do sistema imune inato, resulta em uma inflamação sistêmica danosa ao hospedeiro. Além disso, esse processo é potencializado pela ativação das mesmas vias de sinalização, mediada pela liberação de padrões associados ao dano (DAMPs), isso em resposta a injuria tecidual causada pela inflamação (BONE; GRODZIN; BALK, 1997; CHAN et al., 2012; DEUTSCHMAN; TRACEY, 2014). A complexidade desse processo pode ser observada pelo padrão de liberação dos mediadores inflamatórios: são produzidos tanto mediadores pró-inflamatórios como exemplo, IL6, TNF e IL-1), como de mediadores anti-inflamatórios, como a IL-10, IL-4 e IL-13, comprometendo a resposta contra o patógeno (HOTCHKISS et al., 2016; VAN DER POLL et al., 2017).

De maneira geral, podemos dizer que a sepse possui duas respostas inflamatórias: uma local, que tem a função de controlar o microrganismo, e uma sistêmica, que é consequência da exacerbação da resposta inflamatória local. A resposta inflamatória sistêmica é responsável pela maioria das alterações fisiopatológicas da sepse, como as lesões teciduais e disfunções de órgãos, 
observadas tanto em pacientes como em modelos experimentais de sepse (DINARELLO, 1997; STEARNS-KUROSAWA et al., 2011).

\subsubsection{NeUtRófiLos}

Durante um processo infeccioso, os neutrófilos são as primeiras células a migrarem para o foco da infecção. Eles possuem importante papel na defesa contra infecções bacterianas, devido ao grande estoque de enzimas proteolíticas e a rápida produção de espécies reativas de oxigênio e nitrogênio, capazes de eliminar bactérias patogênicas (MEDZHITOV; JANEWAY, 2000).

Durante a sepse, a migração de neutrófilos para o foco infeccioso varia de acordo com a gravidade dessa condição, sendo relacionado com a taxa de mortalidade. Nosso grupo de pesquisa, demonstrou-se que após a indução de sepse experimental não grave (também conhecida como moderada), ocorre uma eficiente migração dessas células para o foco inflamatório, com consequentemente clearence bacteriano e aumento de taxa de sobrevida dos animais. Entretanto, quando os animais são submetidos a um estímulo grave, os neutrófilos não conseguem migrar até o foco infeccioso, resultando em disseminação bacteriana, exacerbação da resposta inflamatória e morte (ALVES-FILHO et al., 2008; RIOS-SANTOS et al., 2007). Esse processo ocorre por conta da internalização de receptores quimiotáticos importantes para a migração dessas células, como CXCR2, em resposta a elevada ativação dos neutrófilos via TLRs (ALVES-FILHO; SPILLER; CUNHA, 2010).

Além de neutrófilos terem papel protetor, eliminando microrganismos, essas células também apresentam papel deletério, isso quando migram para órgãos que 
não apresentam infecção, e lá causam lesões através da sua ativação (ALVESFILHO et al., 2008; SOUTO et al., 2011).

\subsection{Monócitos}

Monócitos são um subtipo de leucócitos que podem se diferenciar em macrófagos e células dendríticas (AUFFRAY; SIEWEKE; GEISSMANN, 2009). Além disso, essas células são capazes de combater microrganismos, e participam da patogênese de doenças inflamatórias, como a aterosclerose (SERBINA et al., 2008; WOOLLARD; GEISSMANN, 2010).

A população de monócitos é heterogênea, e as subpopulações destas células são divididas de acordo com o perfil de expressão de receptores de quimiocinas e a presença de moléculas específicas em sua membrana. Em camundongos, a expressão de CD11b e alta expressão de Ly6C, identifica um subtipo que expressa altos níveis de CCR2 e baixos níveis de CX3CR1 (GEISSMANN; JUNG; LITTMAN, 2003; SHI; PAMER, 2011). Esses monócitos que são frequentemente denominados

como inflamatórios ou Ly6C ${ }^{\text {high }}$, representando cerca de 2 a $5 \%$ dos leucócitos circulantes em camundongos (condições homeostáticas). Em condições inflamatórias, esse subtipo é rapidamente recrutado para o tecido acometido (SERBINA et al., 2008).

Uma segunda população de monócitos expressa altos níveis de CX3CR1 e baixos níveis de CCR2 e Ly6C (GEISSMANN; JUNG; LITTMAN, 2003). Na corrente sanguínea, os monócitos Ly6C ${ }^{\text {low }}$ são menos prevalentes do que os inflamatórios, e já foi demonstrado que essas células aderem e migram pelos vasos, processo 
denominado patrolling, que compreende na checagem da homeostase de células endoteliais (AUFFRAY et al., 2007).

Em humanos, os monócitos são divididos de acordo com a expressão de CD14 e CD16. Monócitos CD14 ${ }^{\text {high }}$ CD16 $^{-}$compreende a população mais prevalente, eles são denominados como monócitos clássicos e são similares aos monócitos inflamatórios de camundongos (ZIEGLER-HEITBROCK et al., 2010). A população CD16+ é ainda subdividia em duas populações de acordo com a expressão elevada de CD14 ou CD16 , (1) (CD14 ${ }^{\text {high }}$ e CD16+), denominada intermediária, e (2) (CD14 CD16 $\left.{ }^{\text {high }}\right)$ que é denominado de monócito não clássico. Esta última se assemelha aos monócitos murinos Ly6C ${ }^{\text {low }}$ (CROS et al., 2010; SHI; PAMER, 2011; ZIEGLERHEITBROCK, 2007).

\subsubsection{MONÓCITOS INFLAMATÓRIOS}

Monócitos inflamatórios estão envolvidos no controle de diferentes infecções, como bacterianas, causadas por Klebsiella Pneumoniae, Listeria monocytogenes, Mycobacterium tuberculosis (KURIHARA et al., 1997; PETERS et al., 2001; XIONG et al., 2016); por protozoários, como Toxoplasma gondii (DUNAY et al., 2008); por fungos, Cryptococcus neoformans (TRAYNOR et al., 2002); e infecções virais, como pelo West Nile vírus (TSOU et al., 2007). Eles já foram descritos na patofisiologia de inúmeras doenças inflamatórias, como a aterosclerose e câncer (MADSEN et al., 2017; WOOLLARD; GEISSMANN, 2010).

O CCR2 é o principal receptor de quimiocinas presente em monócitos inflamatórios que medeia a migração dessas células a partir da medula óssea para o 
local da inflamação. Essa migração ocorre em resposta aos ligantes CCL2 e CCL7 (SHI et al., 2011; TSOU et al., 2007). Além do CCR2, outros receptores também são importantes nesse processo, como CCR1 e CCR5 (WEBER et al., 2001).

No contexto da sepse, foi observado que monócitos circulantes de pacientes apresentavam expressão gênica aumentada de diversas quimiocinas, citocinas, moléculas de superfície e fatores de transcrição, como exemplo CCL3, CCL5, IL1 $\beta$, IL6; além de um aumento da ativação de NF-KB, fagocitose e killing. Esses achados ressaltam a contribuição de monócitos circulantes no processo inflamatório sistêmico característico da sepse (PACHOT et al., 2006; SHALOVA et al., 2015). Quando essas células, foram estimuladas em cultura com LPS, observou-se uma redução na expressão de $C C L 3,4$, 5; CXCL2, 11; IL1RA, IL1B, IL1 e TNF, diminuição da

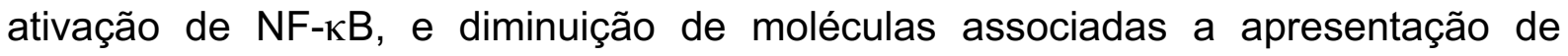
antígenos (CD80, CD40 e HLA-DR). Por outro lado, a fagocitose e a atividade microbicida, bem como a atividade de remodelamento tecidual, permaneceram não alterados (DANIKAS et al., 2008; KIM et al., 2010; MANJUCK et al., 2000; SHALOVA et al., 2015). Esses achados demonstram, que monócitos sofrem plasticidade frente a inflamação durante a sepse. Eles adquirem um fenótipo de tolerância a endotoxinas (endotoxin tolerance), contribuindo com a transição da fase inflamatória para a fase de imunossupressão (BISWAS; LOPEZ-COLLAZO, 2009; ESCOLL et al., 2003; MUNOZ et al., 1991; SHALOVA et al., 2015).

Mais recentemente, monócitos inflamatórios foram descritos por serem importantes mediadores no processo de prejuízo cognitivo na sepse, isso por conta de sua migração e ativação no sistema nervoso central (ANDONEGUI et al., 2018). Por outro lado, a migração de monócitos inflamatórios para os rins, foi descrita como 
protetora, pois preveniu da lesão dos órgãos e aumentou a taxa de sobrevida em animais (CHOUSTERMAN et al., 2016).

Apesar de descrita na patofisiologia da sepse, a função dos monócitos inflamatórios ainda não é muito bem compreendida. Ao mesmo tempo que essas células podem participar do controle de infecções, elas também podem contribuir com inflamação sistêmica e lesão de órgãos. Deste modo, a compreensão do papel dessas células se faz importante para determinação de novos alvos terapêuticos para essa condição clínica. 


\section{HipÓtese}

Apesar de descrito o envolvimento dos monócitos inflamatórios na patofisiologia da sepse, os mecanismos responsáveis por estes efeitos ainda não são muito bem compreendidos. Ao mesmo tempo que essas células podem participar do controle de infecções, elas também podem contribuir com inflamação sistêmica e lesão de órgãos. Devido a esse papel dual, as hipóteses do trabalho foram:

- Monócitos inflamatórios são células importantes para o controle da infecção, protegendo o animal da sepse.

- Monócitos inflamatórios contribuem com a exacerbação da inflamação e lesões de órgãos. 


\section{OBjetivos}

\subsection{OBJETIVO GERAL}

Determinar o papel de monócitos inflamatórios na sepse.

\subsection{OBJetivos ESPECíficos}

- Avaliar as diferenças na cinética de migração de monócitos inflamatórios para o foco inflamatório e órgãos, na sepse experimental moderada e grave;

- Avaliar a consequência da modulação da quantidade de monócitos inflamatórios na patogênese da sepse. 


\section{MATERIAIS E MÉTODOS}

\subsection{ANIMAIS DE EXPERIMENTAÇÃo}

Foram utilizados camundongos da linhagem C57BL/6, provenientes do biotério central da Universidade de São Paulo (USP) - Campus de Ribeirão Preto. Além disso, foram utilizados animais deficientes para CCR2, provenientes do biotério de camundongos especiais da mesma universidade, que foram adquiridos da Jackson Laboratory ( $\mathrm{n}^{\circ}$ : 004999). Os animais foram mantidos no biotério departamental da Farmacologia da Faculdade de Medicina de Ribeirão Preto (FMRP), sob condições controladas de ciclo claro/escuro, umidade, temperatura e alimentação ad libitum. Nos experimentos que foram comparados camundongos wildtype (WT) e deficientes para CCR2, os animais ficaram em cohouse por pelo menos 1 mês para pareamento da microbiota. Os experimentos foram aprovados e conduzidos de acordo com o comitê de ética de animais de experimentação da Faculdade de Medicina de Ribeirão Preto (número de registro: 080/2018).

\subsection{INDUÇÃO DE SEPSE}

Os animais foram anestesiados com anestésico inalatório (isoflurano 1,5\%) e em seguida foi realizada tricotomia e desinfecção com álcool-iodado da região abdominal. Posteriormente, foi realizada incisão de $1 \mathrm{~cm}$ no abdômen para ter-se acesso a cavidade peritoneal e exposição do ceco. O conteúdo cecal foi movido 
gentilmente para a porção distal do ceco, em seguida o conteúdo foi aprisionado utilizando uma ligadura, com linha de algodão. Após esse procedimento, duas perfurações com uma agulha de calibre de 23G foram realizadas no ceco dos animais para indução da sepse moderada, e o mesmo procedimento, porém com agulha de calibre de $16 \mathrm{G}$, foi realizado para sepse grave. Em seguida, o ceco foi pressionado gentilmente para saída das fezes pelas perfurações e colocado de volta no interior da cavidade abdominal, sendo a incisão suturada. Após a cirurgia, foi administrado $1 \mathrm{~mL}$ de solução salina por via subcutânea, para hidratação, e os animais foram deixados sob exposição de luz incandescente até a total recuperação da anestesia. Animais pertencentes ao grupo sham foram submetidos à cirurgia, porém não tiveram o ceco perfurado. Após a cirurgia, os animais foram novamente acondicionados no biotério departamental. O acompanhamento da mortalidade foi realizado a cada $12 \mathrm{~h}$, durante 8 dias.

\subsection{Coleta de células do sangue e plasma}

Os animais foram submetidos a eutanásia com injeção intravenosa de Ketamina $\left(100 \mathrm{mg} \cdot \mathrm{kg}^{-1}\right)$ e Xilasina $\left(10 \mathrm{mg} \cdot \mathrm{kg}^{-1}\right)$, através do plexo orbital, juntamente com 10 uL de heparina. Após certificação da morte do animal, o sangue foi coletado através de punção do plexo orbital utilizando capilar com $20 \mathrm{uL}$ de heparina. $\mathrm{O}$ plasma foi separado dos outros hemocomponentes através de centrifugação $(450 \mathrm{~g}$, 5 minutos, $4^{\circ} \mathrm{C}$ ), coletado e condicionado até análise à $-70^{\circ} \mathrm{C}$. 
As células que ficaram separadas do plasma foram ressuspendidas em solução de Tris-Cloreto de amônio (Hudson et al, 1989) para lise de hemácias, e em seguida utilizadas para citometria e contagem total utilizando câmara de Neubauer.

\subsection{Coleta do lavado Peritoneal}

Após eutanásia, foi injetado $1,5 \mathrm{~mL}$ de PBS contendo $1 \mathrm{mM}$ de EDTA na cavidade peritoneal, posteriormente homogeneização, um volume de $1 \mathrm{~mL}$ foi recuperado. O lavado foi centrifugado $\left(450 \mathrm{~g}, 5\right.$ minutos, $\left.4^{\circ} \mathrm{C}\right)$ para coleta do sobrenadante, que foi acondicionado em $-70^{\circ} \mathrm{C}$ até realização da quantificação de citocinas e quimiocinas. O pellet, que contem células, foi submetido a lise de hemácias e em seguida, as células foram utilizadas para citometria e contagem total com a utilização de câmara de Neubauer.

\subsection{Coleta de cÉLulas da medula Óssea}

Após eutanásia, a medula óssea foi coletada através de flushing do conteúdo medular do fêmur e tíbia. Após a coleta, as hemácias foram lisadas, permitindo que as células fossem utilizadas para citometria e contagem total. 


\subsection{Coleta de ÓRgÃos}

Após eutanásia, pulmão e rim foram coletados para análise de citometria e quantificação de citocinas e quimiocinas, sendo que o pulmão e rim esquerdo foi utilizado para citometria e o outro lado, ou outro órgão direito, utilizado para ELISA.

Previamente a coleta, os animais foram eutanasiados e perfundidos com 20 $\mathrm{mL}$ de PBS através de injeção no ventrículo direito e incisão do átrio esquerdo, para saída do sangue e fluído perfundido.

Para citometria, os órgãos foram acondicionados em solução de digestão enzimática contendo $0,5 \mathrm{mg} \cdot \mathrm{mL}^{-1}$ de colagenase do tipo II (Sigma Aldrich - USA) em $2 \mathrm{~mL}$ de meio RPMI incompleto (Corning - USA) por 45 minutos a $37^{\circ} \mathrm{C}$. Após incubação, a digestão foi inibida com adição de $1 \mathrm{~mL}$ de RPMI com soro fetal bovino (Gibco - USA), e o material foi filtrado em cell strainer de 100 uM (Falcon - USA). As hemácias presentes no filtrado foram lisadas e as células utilizadas para citometria e contagem total.

Para quantificação de proteínas, os órgãos foram congelados a $-70^{\circ} \mathrm{C}$ em 200 uL contendo PBS e inibidor de protease 1X (Sigma Aldrich - USA) até o processamento utilizando macerador automático. O macerado foi centrifugado $(450 \mathrm{~g}$ por 10 minutos a $4^{\circ} \mathrm{C}$ ) e o sobrenadante coletado para quantificação de proteínas.

\subsection{CitometriA}

Células do sangue, lavado peritoneal, medula óssea foram condicionadas (10 minutos em temperatura ambiente) em solução de bloqueio de receptores Fc 
utilizando FcBlock (BD Biosciences, Califórnia - USA). Para marcação das células foi utilizado o coquetel de anticorpos: Viability BV421 - 1:1000; Ly6C PerCP - 1:300; Ly6G FITC - 1:300; CD11b APC-Cy7 - 1:300; tempo de marcação 10 minutos em temperatura ambiente. Posteriormente as células foram lavadas com PBS e fixadas com $2 \%$ de paraformaldeído. Monócitos inflamatórios foram definidos como CD11b high , Ly6G' e Ly6C' e neutrófilos como Ly6G $^{+}$. As aquisições de dados foram realizadas utilizando os equipamentos FACSVerse ou FACSCantoll (BD Biosciences, Califórnia - USA). As análises foram realizadas no FlowJo (TreeStar USA), considerando somente singlets e células viáveis (Fig. 1). As análises foram sempre realizadas com os controles de marcação FMO (Fluorescence Minus One).
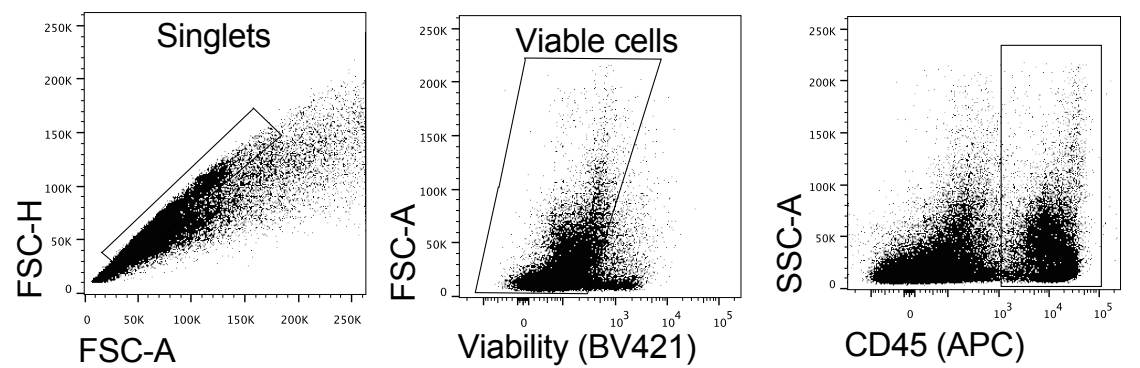

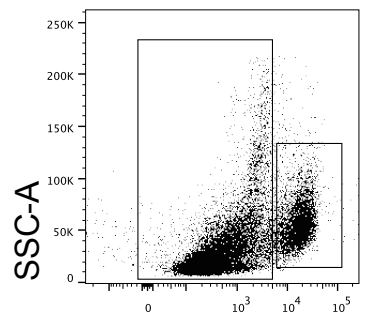

Ly6G (FITC)

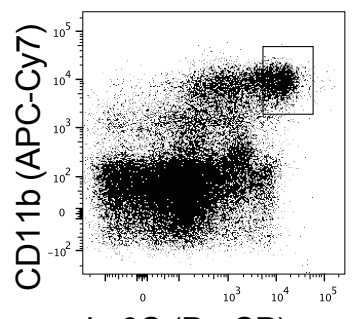

Ly6C (PerCP)

Figura 1: Estratégia de gates de citometria. Primeiramente foram excluídos debris celulares e dublets (gate 1), em seguida foram selecionados os eventos vivos (gate 2), em caso de órgãos, células CD45+ (gate 3). No dotplot 4, foram selecionados os neutrófilos (gate em células Ly6G positivas), os eventos Ly6G negativos foram analisados no dotplot 5 em relação a expressão de CD11b e Ly6C.

\subsection{Cell sorting}


Medula óssea de camundongos foram coletadas através de flushing do conteúdo medular do fêmur e tíbia. Após a coleta, as hemácias foram lisadas com solução de lise, e os receptores Fc foram bloqueados (metodologia anterior). Posteriormente, as células foram marcadas com Viability dye BV421 - 1:1000; Ly6C PerCP - 1:300; Ly6G FITC - 1:300; CD11b APC-Cy7 - 1:300, e sorteadas no FACS cell sorter Arialll (BD Biosciences, Califórnia - USA). Utilizando o método de separação 4-way purity, flowrate de em média 5000 eventos/segundo, eficiência de em média 90\%, nozzel de 85 um. Após a separação a pureza da amostra foi determinada.

\subsection{CONCETRAÇÃO DE QUIMICINAS E CITOCINAS}

Após coleta do lavado peritoneal, plasma e tecidos, as concentrações de citocinas e quimiocinas foram determinadas através de ensaio imunoenzimático (ELISA), seguindo o protocolo do fabricante (R\&D Systems, Minneapolis - USA). Brevemente, o método consistiu no coating de anticorpos de captura em placa de 96 poços durante $12 \mathrm{~h}$ em refrigeração de $4^{\circ} \mathrm{C}$, em seguida, de lavagem dos anticorpos não ligados a placa com PBS-Tween (Sigma Aldrich - USA); bloqueio de ligações inespecíficas com PBS com 0,5\% BSA (Sigma Aldrich - USA) por $2 \mathrm{~h}$ em temperatura ambiente; lavagem; adição de (50 uL) amostras a serem quantificadas e controles: curva de calibração e um poço com ausência de amostra (incubação por 2h em temperatura ambiente); lavagem; adição do anticorpo de detecção (incubação por $2 \mathrm{~h}$ em temperatura ambiente); lavagem; adição de solução $1 \mathrm{X}$ de estreptoavidina por 30 minutos em temperatura ambiente; lavagem; adição de 
substrato colorimétrico TMB (tetrametilbenzidina; Sigma); e solução para inibição da reação, $\mathrm{H}_{2} \mathrm{SO}_{4}(1 \mathrm{M})$. As reações foram lidas em equipamento de espectrofotometria em comprimento de onda de 450 nm (Spectra Max-250, Molecular Devices).

As concentrações de citocinas e quimiocinas foram expressas em picogramas por $\mathrm{mL}(\mathrm{pg} / \mathrm{mL})$ ou em nanogramas por $\mathrm{mL}(\mathrm{ng} / \mathrm{mL})$. No caso da determinação dos níveis de citocinas e quimiocinas de tecidos, a quantificação por ELISA foi normalizada através da quantidade de proteína total quantificada pelo método do ácido bicinconínico (BCA) (Smith et al., 1985), que consiste na reação de ligações peptídicas com Cobre $(\mathrm{Cu}+2)$ que o reduz $(\mathrm{Cu}+)$, o qual interage com o $\mathrm{BCA}$ alterando a cor da solução (reação foi realizada a $37^{\circ} \mathrm{C}$ por 30 minutos), que é quantificada por espectrofotometria em comprimento de onde de $561 \mathrm{~nm}$ (Spectra Max-250, Molecular Devices).

\subsection{QUANTIFICAÇÃo dE BACTÉRIAS}

Amostras de sangue e lavado peritoneal foram coletadas após a CLP e diluídas para quantificação de bactérias viáveis. No caso do lavado peritoneal, as diluições foram de 1:100, 1:1000, e 1:10000, já o sangue foi plaqueado puro ou na diluição de 1:10. As diluições foram semeadas em placas de Petri contendo meio Agar Müller-Hinton (Difco Laboratories) e incubadas a $37^{\circ} \mathrm{C}$ por 18 horas. O número de unidades formadoras de colônias (UFC) foi registrado e considerado equivalente ao número de bactérias viáveis nas amostras avaliadas. Os resultados foram expressos em Log de UFC por $\mathrm{mL}$ (UFC/mL). 


\subsection{ATIVIDADE MICROBICIDA E QUANTIFICAÇÃO DE NITRITO}

Monócitos inflamatórios foram sorteados, e $1 \times 10^{5}$ células foram incubadas com E. coli $\left(1 \times 10^{6} \mathrm{CFU}\right)$ por 45 minutos, a temperatura e níveis de $\mathrm{CO}_{2}$ controlados $\left(37^{\circ} \mathrm{C}\right.$ e $5 \%$ de $\left.\mathrm{CO}_{2}\right)$. Como controle, as mesmas quantidades de bactérias foram incubadas sem adição de células. Depois disso, as amostras foram homogeneizadas e a quantidade de bactérias extracelulares foram determinadas pela contagem de unidades formadoras de placa após semeadura em placas com agar Mueller-Hinton. Após isso as células foram incubadas por 30 minutos com gentamicina $\left(50 \mathrm{mg} \cdot \mathrm{mL}^{-1}\right)$ a $37^{\circ} \mathrm{C}$ e $5 \%$ de $\mathrm{CO}_{2}$, posteriormente foram lavadas com $0,2 \%$ de Triton $\mathrm{X}-100$, e determinou-se a quantidade de bactérias CFU viáveis intracelulares. A atividade bactericida foi definida como: (CFU extracelular + CFU intracelular) / CFU do controle. Os resultados foram expressos em porcentagem de atividade microbicida em relação ao controle.

A concentração de nitrito no sobrenadante foi determinada pela reação de GRIES (Green et al., 1982). O resultado foi expresso em uM de Nitrito.

\subsection{MARCADORES DE LESÕES DE ÓRGÃOS}

Marcadores de lesões de órgãos, como CK-MB, uréia, TGO e TGP foram determinados através de kits laboratoriais (BioClin, Minas Gerais - Brasil). Os resultados foram expressos de acordo com o protocolo específico de cada teste. 


\subsection{ANÁLISE ESTATÍSTICA}

A análise da curva de sobrevida de animais submetidos a sepse foi analisada utilizando o teste Mantel-Cox logrank. Os demais resultados foram avaliados por análise de variância (ANOVA), seguida pelo teste de correção Boferroni. Os resultados foram expressos em média e desvio padrão da média. Em todas as análises foi adotado o nível de significância de $p>0,05$, e foram realizadas utilizando o software Prism7 (GraphPad Inc., Califórnia - USA). 


\section{Resultados}

\subsection{ANIMAIS COM SEPSE GRAVe APRESENTAM FALÊNCIA NA MIGRAÇÃo DE MONÓCITOS INFLAMATÓRIOS PARA O FOCO INFECCIOSO}

Para determinar o papel de monócitos inflamatórios na sepse, inicialmente comparamos a cinética de migração dessas células para o foco infeccioso após indução de diferentes gravidades da doença. Para indução da sepse, utilizamos o modelo experimental de ligação e perfuração do ceco (CLP - cecal ligation and puncture) de gravidade moderada, em que os animais apresentam uma taxa de mortalidade de 50\%, e grave, com 100\% de mortalidade (Fig. 2A). Uma vez que já está descrito na literatura um aumento do número de neutrófilos no foco infeccioso após indução da sepse moderada, enquanto que na grave, há uma falência na migração dessas células (ALVES-FILHO et al., 2008; ALVES-FILHO; SPILLER; CUNHA, 2010), avaliamos o número de neutrófilos na cavidade peritoneal dos animais como controle de gravidade dos nossos experimentos.

Durante um processo inflamatório, células sanguíneas são inicialmente recrutadas da medula óssea para o sangue, para posteriormente migrarem para o foco da inflamação. Nesse sentido, resolvemos avaliar também se existe diferença no número de monócitos inflamatórios e neutrófilos na medula óssea e no sangue após indução de uma sepse moderada e grave. De maneira interessante, observamos semelhante diminuição no número de monócitos inflamatórios e neutrófilos após a indução tanto da sepse moderada como grave na medula óssea (Fig. 2B). Por outro lado, enquanto observamos um aumento no número de 
monócitos inflamatórios na circulação após 6 horas da indução de sepse moderada, esse aumento não foi observado após indução da sepse grave (Fig. 2C). Com relação ao número de neutrófilos circulantes, não observamos diferença entre as diferentes gravidades de sepse (Fig. 2C).

Posteriormente avaliamos o recrutamento dos monócitos e neutrófilos para a cavidade peritoneal. Semelhante ao observado com os neutrófilos observou-se menor infiltrado de monócitos inflamatórios na sepse grave quando comparada com a gravidade moderada para o local da infecção (Fig. 2D).

Em conclusão, observamos que na sepse grave, como já é descrito para neutrófilos, monócitos inflamatórios também apresentam falência de migração para o foco inflamatório.
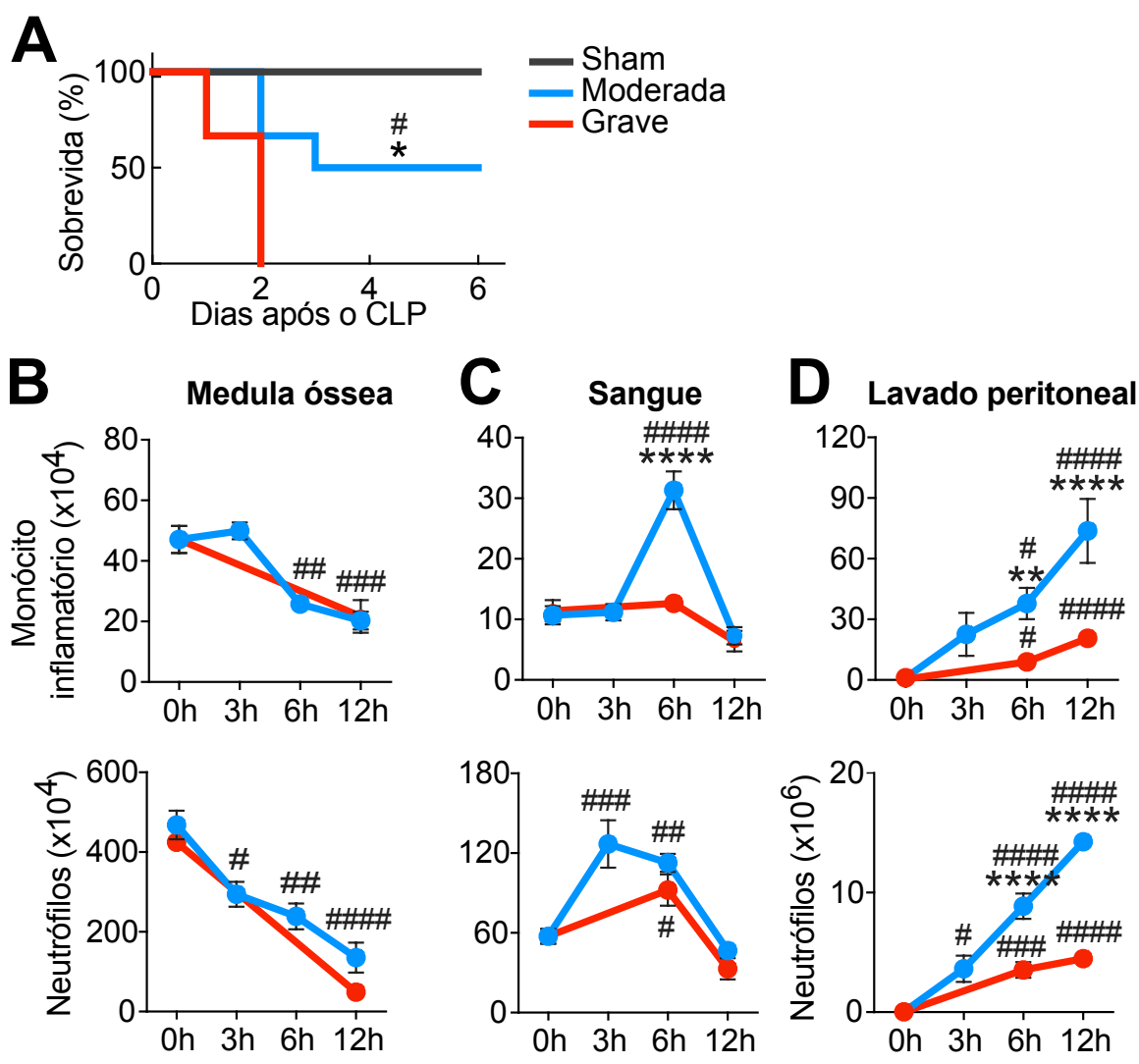

Figura 2: Animais submetidos a sepse letal apresentam falência na migração de monócitos inflamatórios e neutrófilos para o foco infeccioso. Sobrevida dos animais submetidos à sepse moderada e grave (A). Número de monócitos inflamatórios $\left(C D 11 b^{+}\right.$, Ly6C $C^{\text {high }}$ e Ly6G', painéis de cima) e neutrófilos ( $\left(\mathrm{L} 6 \mathrm{G}^{+}\right.$, painéis de baixo) na medula óssea (B), sangue (C) e lavado peritoneal (D) avaliados por citometria de fluxo. Os resultados são representativos de dois experimentos realizados 
independentemente com 5 animais por grupo e estão expressos como média \pm erro padrão da média (ANOVA com correção de Bonferroni, nível de significância: $p<0,05$ ). A avaliação da diferença na curva de sobrevida foi analisada utilizando o teste Mantel-Cox logrank (nível de significância: $p<0,05$ ). ${ }^{*} p<0,05 ;{ }^{* *} p<0,009 ;{ }^{* * *} p<0,0009 ;{ }^{* * * *} p<0,0001 .{ }^{*}$ representa a comparação entre os grupos sepse moderada e grave. \# representa a comparação entre os grupos sham (0h) e indução de sepse (3h, $6 \mathrm{~h}$ e 12h).

\subsection{ANIMAIS COM SEPSE GRAVE APRESENTAM MAIOR INFILTRADO DE MONÓCITOS INFLAMATÓRIOS NO PULMÃO}

Uma vez demonstrado que apesar do número de monócitos que saem da medula ser semelhante após indução das diferentes gravidades de sepse, observase essas células estão reduzidas na circulação e foco inflamatório dos animais submetidos à sepse grave. O nosso próximo passo foi avaliar se esses monócitos estariam sendo retidos em órgãos periféricos após indução da sepse grave. De fato, trabalhos demonstram que neutrófilos são ativados durante a sepse letal, acarretando na sua rápida aderência na vasculatura e migração a órgãos (SÔNEGO et al., 2016). Para testar nossa hipótese, coletou-se o pulmão de camundongos submetidos a sepse moderada e grave após 12 horas e de maneira bastante interessante observou-se um aumento na frequência e número de monócitos inflamatórios na sepse grave em comparação com a moderada (Fig. 3A). Como esperado, o mesmo fenômeno foi observado em relação aos neutrófilos (Fig. 3B).

Em conclusão, demonstrou-se que monócitos inflamatórios, durante a sepse grave, estão em menor quantidade no foco inflamatório, porém estão em maior frequência no pulmão. Desse modo, sugere-se que a ausência dessas células no ambiente infecioso acarreta descontrole na eliminação de microrganismos levando à indução de uma resposta inflamatória sistêmica. Como consequência, os monócitos 
são ativados na circulação e acabam migrando para outros órgãos, como os pulmões, podendo contribuir para o aumento das lesões orgânicas observadas na sepse.
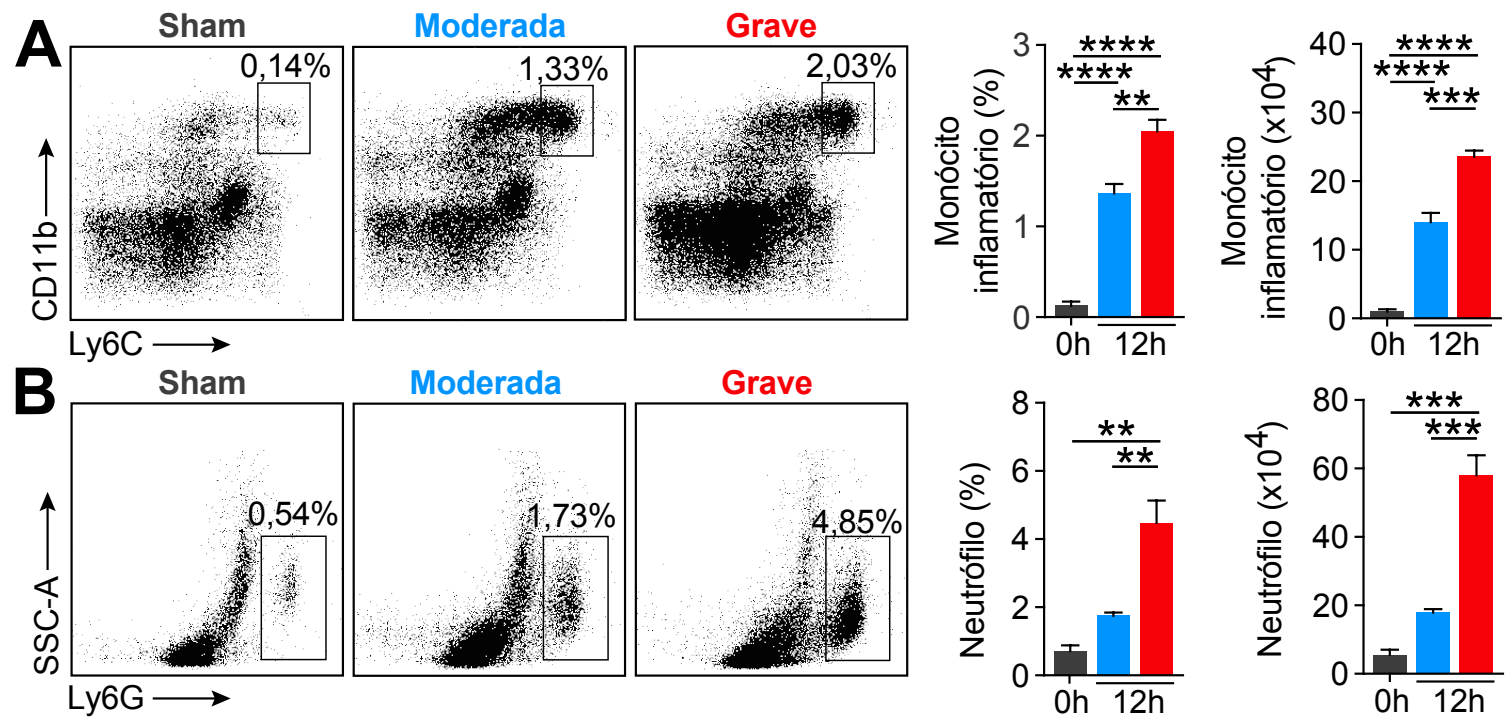

Figura 3: Animais submetidos a sepse grave apresentam maior infiltrado de monócitos inflamatórios e neutrófilos no pulmão. Dotplot representativo, frequência e número de $(A)$ monócitos inflamatórios (CD11 b ${ }^{+}$, Ly6C $^{\text {high }}$ e Ly6G $^{-}$) e (B) neutrófilos $\left(\mathrm{Ly}_{6 \mathrm{G}}{ }^{+}\right)$avaliados $12 \mathrm{~h}$ após a indução de sepse moderada (azul) e grave (vermelho). Os resultados são representativos de dois experimentos realizados independentemente com 5 animais por grupo, e estão expressos como média \pm erro padrão da média (ANOVA com correção de Bonferroni, nível de significância: $p<0,05$ ). * $p<0,05$ a $p=0,01 ;{ }^{* *} p<0,009$ a $p=0,001 ;{ }^{* * *} p<0,0009$ a $p=0,0001 ;{ }^{* * * *} p<0,0001$.

\subsection{ANIMAIS CCR2 ${ }^{-/-}$APRESENTAM DEFICIÊNCIA NA EMIGRAÇÃO DE MONÓCITOS INFLAMATÓRIOS DA MEDULA ÓSSEA E MENOR FREQUÊNCIA DESSAS CÉLULAS NO LOCAL DA INFECÇÃO}

Camundongos geneticamente deficientes para CCR2 apresentam diminuição na emigração de monócitos inflamatórios da medula óssea para a periferia. Desse modo, esses animais são uma ferramenta interessante para avaliar o papel dessas células durante a sepse (SERBINA; PAMER, 2006). Com isso, nos determinamos a frequência de monócitos inflamatórios na medula óssea e lavado peritoneal de 
animais WT e CCR2 ${ }^{-/-}$. Como esperado, não se observou diminuição do número de monócitos inflamatórios na medula óssea de animais $\mathrm{CCR}^{-/-}$durante a sepse, diferentemente de animais WT (Fig. 4A). Além disso, observou-se menor aumento da frequência e número dessa população celular no foco inflamatório (Fig. 5B). Por outro lado, não se observou influência da ausência desse receptor na emigração de neutrófilos da medula (Fig. 4B). Observou-se ainda maior aumento do número dessas células no foco inflamatório nos animais CCR2 ${ }^{-/-}$(Fig. 6). Deste modo, esses dados demonstram que a deficiência de CCR2 prejudicou a emigração de monócitos inflamatórios da medula óssea para o foco inflamatório no contexto da sepse.

Uma vez demonstrado que animais $\mathrm{CCR}^{-/-}$apresentam redução na migração de monócitos inflamatórios para o foco infeccioso durante a sepse, o nosso próximo passo foi excluir se esse fenômeno poderia ser decorrente de uma menor resposta inflamatória gerada no início da infecção nesses animais. Uma das células mais abundantes na cavidade peritoneal em condições homeostáticas é o macrófago grande (CD11bigh, Ly6G $^{-}$e Ly6C $\left.^{-}\right)$. Com isso, resolvemos investigar se animais $\mathrm{CCR}^{-/-}$apresentavam redução no número dessas células na cavidade peritoneal. Como podemos observar na Figura 4A, não houve diferença no número de macrófagos grandes na cavidade peritoneal de animais WT e CCR2-/-. Além disso, quando avaliamos os níveis de quimiocinas e citocinas no foco infeccioso desses animais após indução da sepse, não encontramos diferenças nas quantidades de CCL2, CXCL2, IL-6 e IL-10 no lavado peritoneal entre animais CCR2-/- e WT (Fig. 7).

Em conclusão, os nossos dados sugerem que o menor número de monócitos inflamatórios na cavidade peritoneal dos animais deficientes para CCR2 é 
decorrente de uma menor emigração dessas células da medula óssea, via ativação do CCR2, e não de uma falha na montagem inicial da resposta inflamatória.
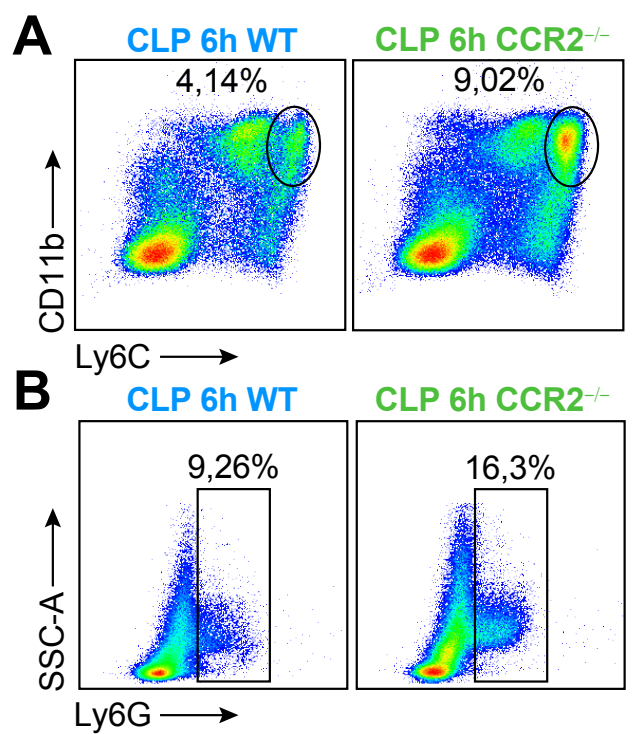
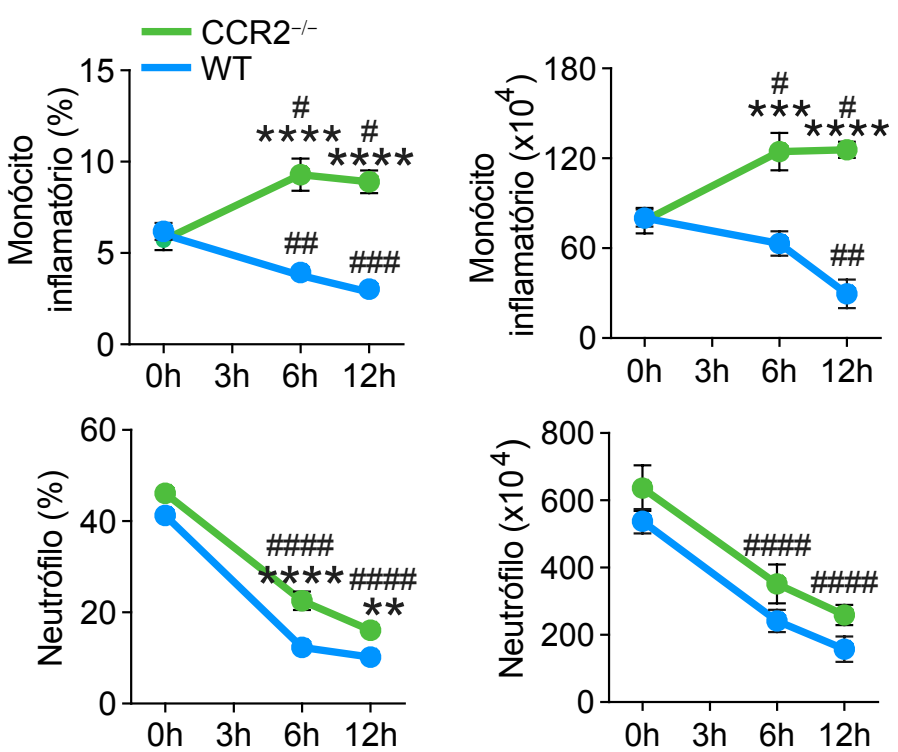

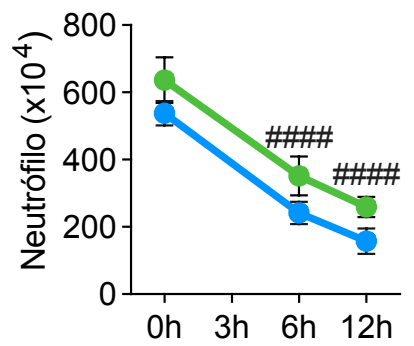

Figura 4: Animais deficientes para CCR2 apresentam menor emigração de monócitos inflamatórios da medula óssea, porém a emigração de neutrófilos é semelhante aos animais WT. Dotplot representativo, frequência e número de $(A)$ monócitos inflamatórios $\left(C D 11 b^{+}, L_{6 y} C^{\text {high }}\right.$ e Ly6G') e (B) neutrófilos $\left(\mathrm{Ly}_{6 \mathrm{G}} \mathrm{G}^{+}\right.$) presentes na medula óssea de animais controles (Oh) e após a indução de sepse moderada. Os resultados são representativos de dois experimentos realizados independentemente com 5 animais por grupo, e estão expressos como média \pm erro padrão da média (ANOVA com correção de Bonferroni, nível de significância: $p<0,05)$. * $p<0,05$ a $p=0,01 ;{ }^{* *} p<0,009$ a $p=0,001 ;{ }^{* * *} p<0,0009$ a $p=0,0001 ;{ }^{* * * *} p<0,0001$. ${ }^{*}$ representa a comparação entre os grupos CCR2 KO e WT \# representa a comparação entre os grupos sham (0h) e indução de sepse (3h, 6h e 12h).
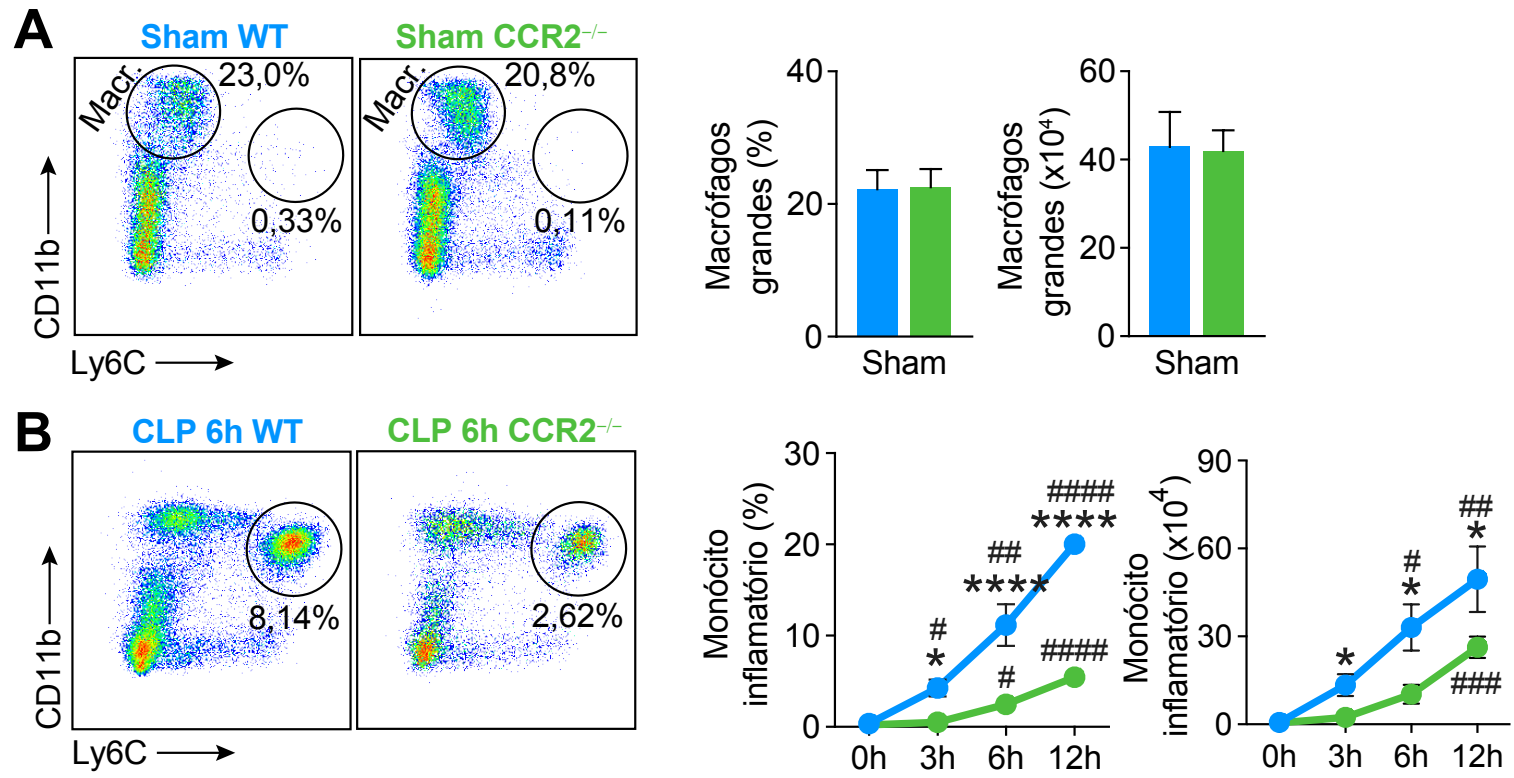
Figura 5: Animais deficientes para CCR2 apresentam menor migração de monócitos inflamatórios para a cavidade peritoneal. Dotplot representativo, frequência e número de $(A)$ macrófagos grandes (CD11b ${ }^{\text {high }}$, Ly6C $C^{-}$e Ly6G) e (B) monócitos inflamatórios (CD11b ${ }^{+}$, Ly6C ${ }^{\text {high }}$ e Ly6C') presentes na cavidade peritoneal de animais controles (Oh) e após a indução de sepse moderada. Os resultados são representativos de dois experimentos realizados independentemente com 5 animais por grupo, e estão expressos como média \pm erro padrão da média (ANOVA com correção de Bonferroni, nível de significância: $p<0,05)$. * $p<0,05$ a $p=0,01 ;{ }^{* *} p<0,009$ a $p=0,001$; *** $p<0,0009$ a $p=0,0001 ;{ }^{* * * *} p<0,0001$. * representa a comparação entre os grupos sepse CCR2 KO e WT. \# representa a comparação entre os grupos sham (Oh) e indução de sepse (3h, $6 \mathrm{~h}$ e $12 \mathrm{~h}$ ).
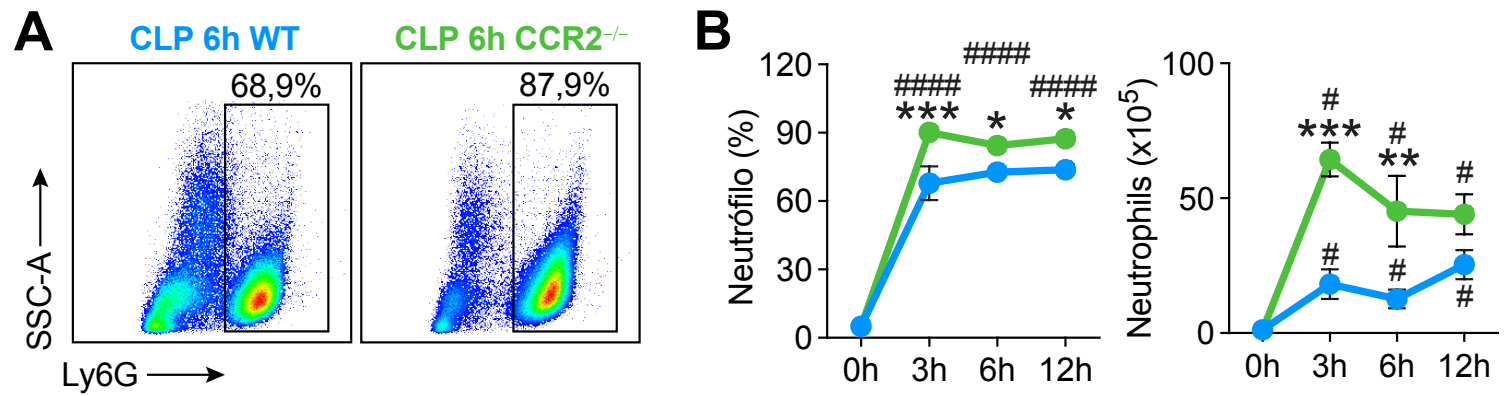

Figura 6: Animais deficientes para CCR2 apresentam maior migração de neutrófilos para a cavidade peritoneal. Dotplot representativo $(A)$, frequência e número de $(B)$ neutrófilos $\left(\mathrm{Ly}_{6} \mathrm{G}^{+}\right)$ presentes na cavidade peritoneal de animais controles (0h) e após a indução de sepse moderada. Os resultados são representativos de dois experimentos realizados independentemente com 5 animais por grupo, e estão expressos como média \pm erro padrão da média (ANOVA com correção de Bonferroni, nível de significância: $p<0,05)$. ${ }^{*} p<0,05$ a $p=0,01 ;{ }^{* *} p<0,009$ a $p=0,001 ;{ }^{* * *} p<0,0009$ a $p=0,0001 ;{ }^{* * * *} p<0,0001 .{ }^{*}$ representa a comparação entre os grupos CCR2 KO e WT. \# representa a comparação entre os grupos sham (0h) e indução de sepse (3h, 6h e 12h).
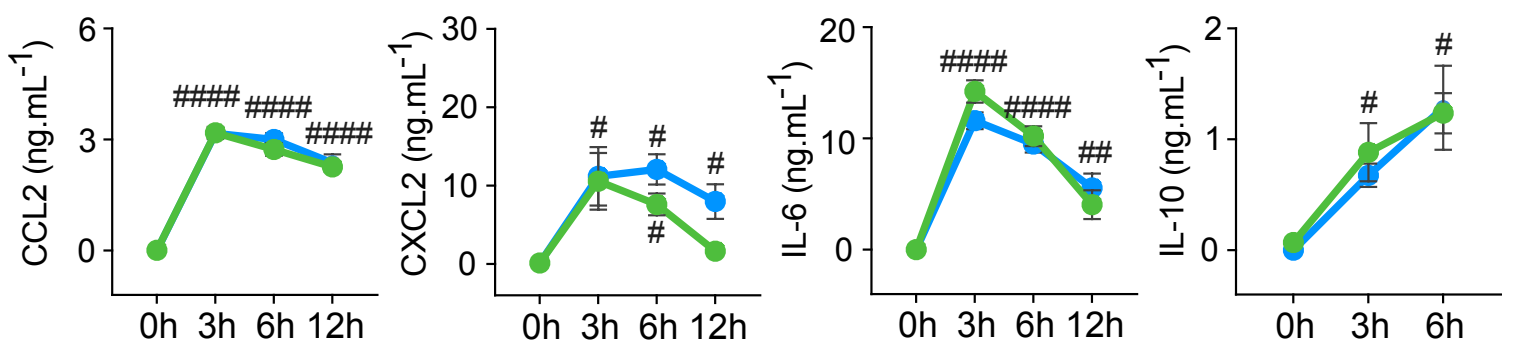

Figura 7: Animais deficientes para CCR2 e WT não possuem diferença nos níveis de citocinas e quimiocinas no foco inflamatório quando submetidos à sepse moderada. Os níveis de CCL2, CXCL2, IL-6 e IL-10 foram quantificadas por ELISA no lavado peritoneal coletado de animais WT e $\mathrm{KO}$, controles ou submetidos à sepse moderada. Os resultados são representativos de dois experimentos realizados independentemente com 5 animais por grupo, e estão expressos como média \pm erro padrão da média (ANOVA com correção de Bonferroni, nível de significância: $p<0,05$ ). * $p<0,05$ a $p=0,01 ;{ }^{* *} p<0,009$ a $p=0,001 ;{ }^{* * *} p<0,0009$ a $p=0,0001 ;{ }^{* * *} p<0,0001 .{ }^{*}$ representa a comparação entre os grupos CCR2 KO e WT. \# representa a comparação entre os grupos sham (0h) e indução de sepse (3h, 6h e 12h). 


\subsection{ANimals Deficientes PARA CCR2 APRESENTAM MAIOR SOBREVIDA EM RELAÇÃO AOS ANIMAIS WT, PORÉM NÃO APRESENTAM DIFERENÇA NA CARGA BACTERIANA E NÍVEIS DE CITOCINAS E QUIMIOCINAS NO FOCO INFLAMATÓRIO}

Uma vez demonstrado que animais deficientes para CCR2 apresentam menor número de monócitos inflamatórios na cavidade peritoneal após indução de uma sepse moderada, o nosso próximo passo foi investigar se esses animais são mais suscetíveis à sepse. No entanto, de maneira interessante observou-se que animais deficientes para CCR2 são mais resistentes a sepse (Fig. 8A). A fim de entender a maior resistência dos animais $\mathrm{CCR}^{-/-}$avaliamos a carga bacteriana no foco infeccioso e sua disseminação para a circulação. Como podemos observar na figura 8B, animais WT e deficientes para CCR2 não apresentaram diferença na carga bacteriana no lavado peritoneal e no sangue, e como já mencionado, não apresentaram diferença na produção de quimiocinas e citocinas no lavado peritoneal (Fig. 7).

Deste modo, animais deficientes para CCR2 apresentam maior sobrevida em relação ao WT, porém esse efeito é independente do controle bacteriano. No entanto, é conhecido que monócitos participam do controle da infecção. De fato, quando isolamos monócitos inflamatórios e incubamos, in vitro, com bactéria extracelular observamos uma redução do número de bactérias viáveis, indicando que monócitos possuem atividade fagocíticas e microbicida (Fig. 9A), os quais produzem óxido nítrico (Fig. 9B). Assim, esperava-se que a menor migração dessas células prejudicaria o controle da infecção. Porém, nesse caso, sugere-se que esse prejuízo é suprido pela maior presença de neutrófilos, que participam da eliminação dos microrganismos, como demonstrado na Fig. 6B. 
A

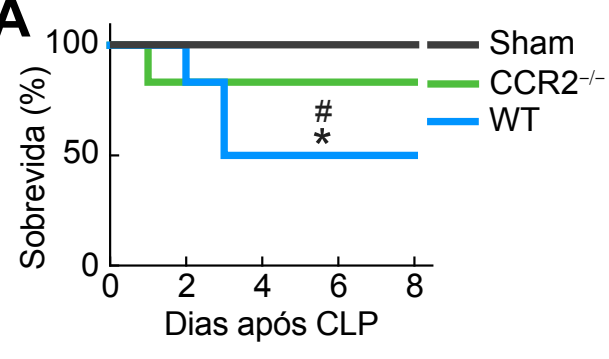

B

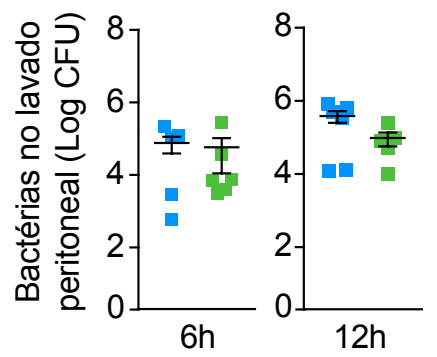

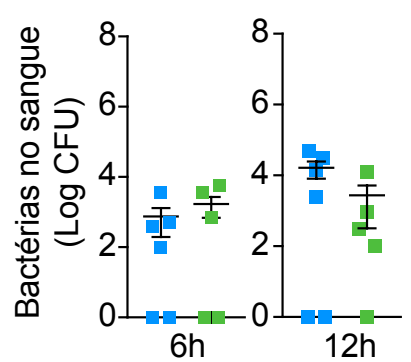

Figura 8: Animais deficientes para CCR2 apresentam maior sobrevida a sepse, porém similar carga bacteriana no sangue e foco infeccioso. Sobrevida após a indução de sepse moderada comparando animais WT (azul) e animais deficientes para CCR2 (verde) (A). Carga bacteriana avaliada no lavado peritoneal e sangue, após $6 \mathrm{~h}$ e $12 \mathrm{~h}$ da indução de sepse moderada nos animais WT e KO (B). Os resultados são representativos de dois experimentos realizados independentemente com 5 animais por grupo. A carga bacteriana foi determinado por contagem de unidades formadora de colônia e representados em LogCFU/mL (tesde de Mann-Whitney, nível de significância: $p<0,05$ ). A avaliação da diferença na curva de sobrevida foi analisada utilizando o teste Mantel-Cox logrank (nível de significância: $p>0,05$ ). * $p<0,05$ a $p=0,01 .{ }^{*}$ representa a comparação entre os grupos CCRw KO e WT. \# representa a comparação entre os grupos sham e WT.

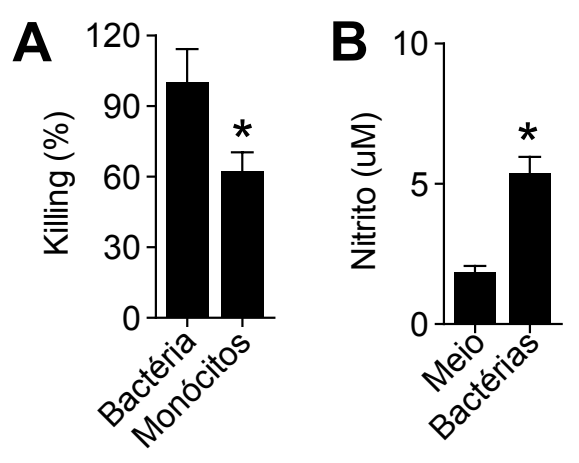

Figura 9: Monócitos inflamatórios possuem atividade microbicida e produzem óxido nítrico. $1 \times 10^{5}$ monócitos foram incubados com $1 \times 10^{6}$ E. coli por 45 minutos e foi quantificado a carga bacteriana do sobrenadante e intracelular para determinar atividade microbicida $(A)$ e foi determinado no sobrenadante os níveis de nitrito (B). Os resultados são representativos de dois experimentos realizados independentemente com 3 replicatas por grupo, e estão expressos como média \pm erro padrão da média (ANOVA com correção de Bonferroni, nível de significância: $p<0,05$ ). ${ }^{*} p<0,05$ a $p=0,01 ;{ }^{* *} p<0,009$ a $p=0,001 ;{ }^{* * *} p<0,0009$ a $p=0,0001 ;{ }^{* * * *} p<0,0001$. 


\subsection{ANIMAIS DEFICIENTES PARA CCR2 APRESENTAM MENORES NÍVEIS DE CXCL2, IL-6 E IL-10 NO PLASMA, ASSIM COMO MENOR PRODUÇÃO DESSAS CITOCINAS E MENOR INFILTRADO DE MONÓCITOS INFLAMATÓRIOS NOS PULMÕES E RINS}

Os nossos dados iniciais demonstraram que durante uma sepse letal ocorre um infiltrado de monócitos inflamatórios no pulmão dos animais (Fig. 3). Inúmeros trabalhos do nosso grupo têm mostrado uma importante participação dos neutrófilos nas lesões orgânicas durante a sepse (ALVES-FILHO et al., 2009, 2005; SÔNEGO et al., 2016). No entanto, pouco se sabe sobre o papel dos monócitos inflamatórios nesse processo. Uma vez que animais deficientes para CCR2 não apresentaram diferença no controle bacteriano durante a sepse e se mostraram mais resistentes à doença, nossa hipótese é que o monócito inflamatório poderia estar tendo um papel deletério na sepse. Para isso, fomos avaliar a resposta inflamatória sistêmica nos animais $\mathrm{CCR}^{-/-}$através de medidas dos níveis de citocinas e quimiocinas sistêmicos, do infiltrado de células em órgãos, e também dos marcadores de lesões orgânicas.

De maneira interessante e corroborando os dados da sobrevida, observou-se que animais $\mathrm{CCR}^{-{ }_{-}}$apresentam menores níveis de CXCL2, IL-6 e IL-10, e níveis semelhantes de CCL2 no plasma em relação aos animais WT (Fig. 9). Além disso, os animais deficientes para CCR2 apresentam menor infiltrado de monócitos inflamatórios no pulmão (Fig. 10A) e rim (Fig. 10B). Curiosamente, apresentam a mesma quantidade de infiltrado de neutrófilos (Fig. 10A e Fig. 10B). Em relação a quantidade de citocinas e quimiocinas em órgãos, observou-se que animais deficientes para CCR2 apresentam menores níveis de IL-6, IL-10, CCL2 e CCL22 no 
pulmão, e IL-6 no rim, isso em relação a animais WT (Fig. 11 e Fig. 12). Em relação aos níveis séricos de marcadores de lesões de órgãos, observou-se que os animais $\mathrm{CCR}^{-/-}$apresentam menores níveis plasmáticos de TGO e CK-MB (Fig. 13).

Em conclusão, esses dados sugerem que a proteção conferida aos animais $\mathrm{CCR}^{-/-}$se dá pela menor migração de monócitos inflamatórios para órgãos, com menor lesão orgânica e inflamação sistêmica.
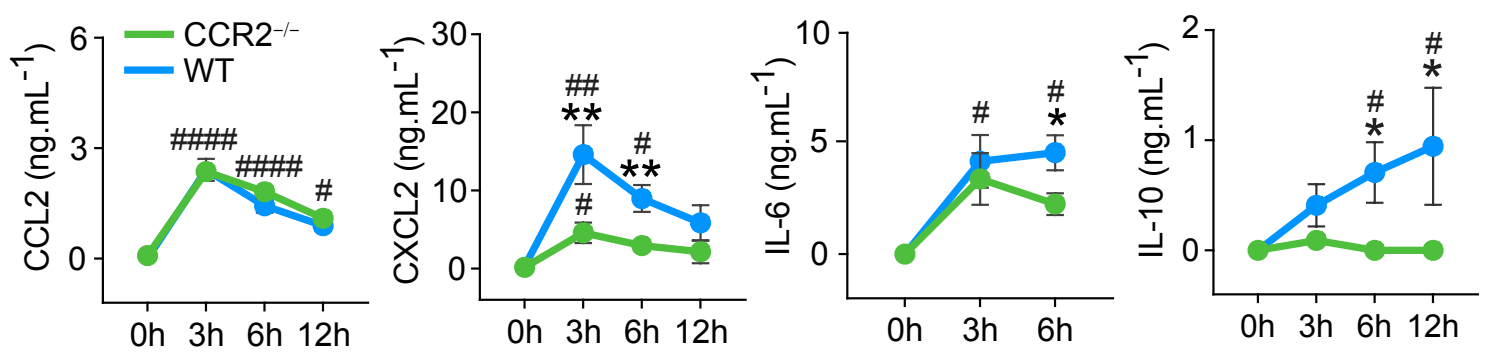

Figura 9: Animais deficientes para CCR2 apresentam menores níveis sistêmicos de CXCL2, IL6 e IL-10, e similares níveis de CCL2 em relação aos animais WT. Citocinas e quimiocinas foram quantificadas por ELISA no plasma coletado de animais deficientes para CCR2 e WT submetidos a sepse moderada. Os resultados são representativos de dois experimentos realizados independentemente com 5 animais por grupo, e estão expressos como média \pm erro padrão da média (ANOVA com correção de Bonferroni, nível de significância: $p<0,05)$. * $p<0,05$ a $p=0,01 ;{ }^{* *} p<0,009$ a $p=0,001 ;{ }^{* * *} p<0,0009$ a $p=0,0001 ;{ }^{* * *} p<0,0001 .{ }^{*}$ representa a comparação entre animais CCR2 KO e WT. \# representa a comparação entre os grupos sham (0h) e indução de sepse (3h, 6h e 12h).

A
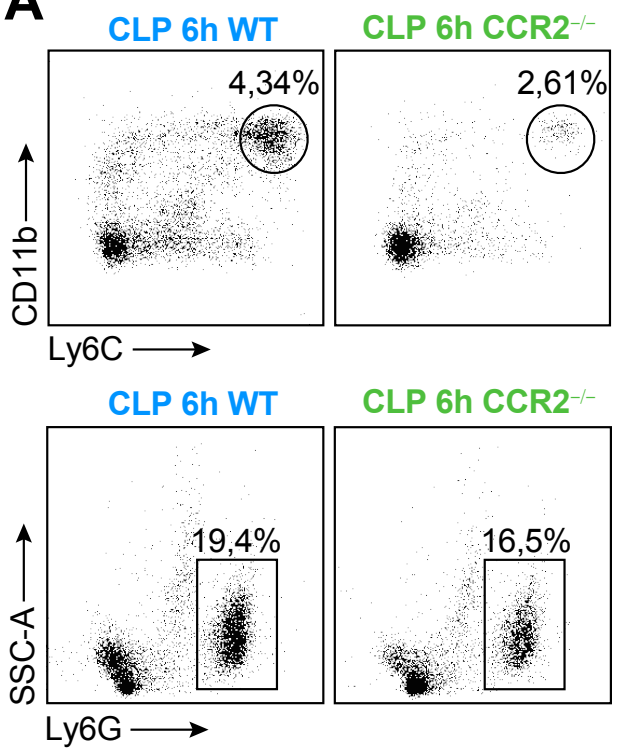
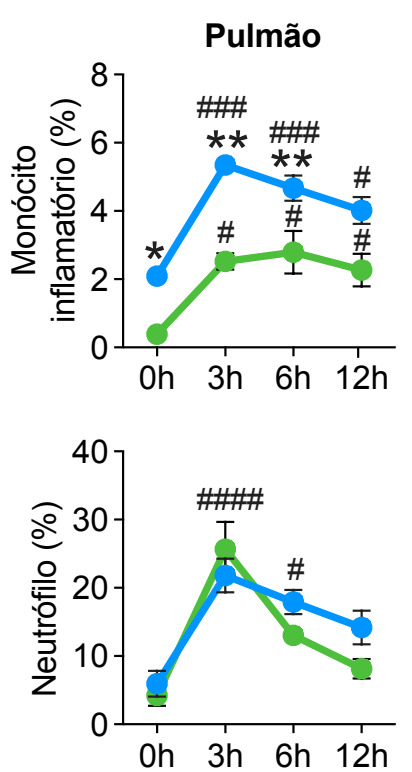

B Rim
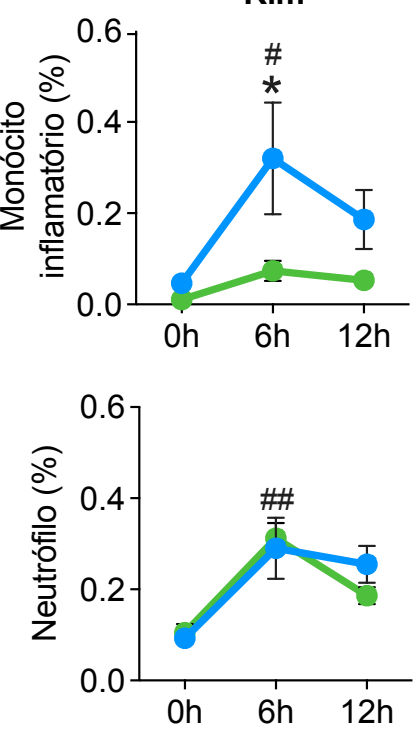

Figura 10: Animais deficientes para CCR2 apresentam menor infiltrado de monócitos inflamatórios no pulmão e rim, porém mesmo infiltrado de neutrófilos. Dotplot representativo e 
frequência de monócitos inflamatórios $\left(C D 11 b^{+}\right.$, Ly6 $C^{\text {high }}$ e $L y 6 C^{-}$, painel de cima) e neutrófilos $\left(\mathrm{Ly} 6 \mathrm{G}^{+}\right.$, painel de baixo) presentes no pulmão (A) e rim (B) de animais controles (Oh) e após a indução de sepse moderada. Os resultados são representativos de dois experimentos realizados independentemente com 5 animais por grupo, e estão expressos como média \pm erro padrão da média (ANOVA com correção de Bonferroni, nível de significância: $p<0,05)$. * $p<0,05$ a $p=0,01 ;{ }^{* *} p<0,009$ a $p=0,001 ;{ }^{* * *} p<0,0009$ a $p=0,0001 ;{ }^{* * * *} p<0,0001 .{ }^{*}$ representa a comparação entre animais CCR2 KO e WT. \# representa a comparação entre os grupos sham (Oh) e indução de sepse (3h, 6h e 12h).
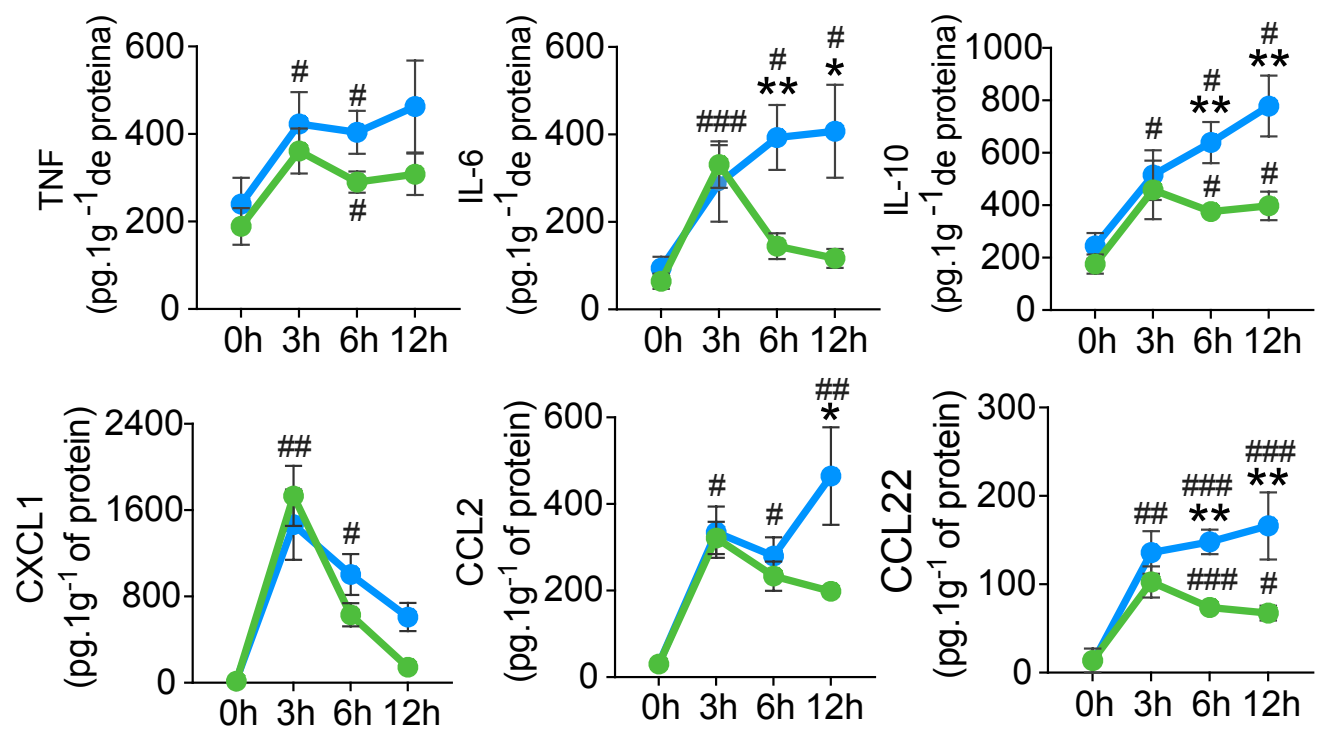

Figura 11: Animais deficientes para CCR2 apresentam menores níveis de citocinas e quimiocinas no pulmão. Citocinas e quimiocinas foram quantificadas por ELISA no tecido pulmonar coletado de animais WT e KO submetidos a sepse moderada. Os resultados são representativos de dois experimentos realizados independentemente com 5 animais por grupo, e estão expressos como média \pm erro padrão da média (ANOVA com correção de Bonferroni, nível de significância: $p<0,05)$. * $p<0,05$ a $p=0,01 ;{ }^{* *} p<0,009$ a $p=0,001 ;{ }^{* * *} p<0,0009$ a $p=0,0001 ;{ }^{* * * *} p<0,0001 .{ }^{*}$ representa a comparação entre animais CCR2 KO e WT. \# representa a comparação entre os grupos sham (Oh) e indução de sepse (3h, $6 \mathrm{~h}$ e $12 \mathrm{~h})$.
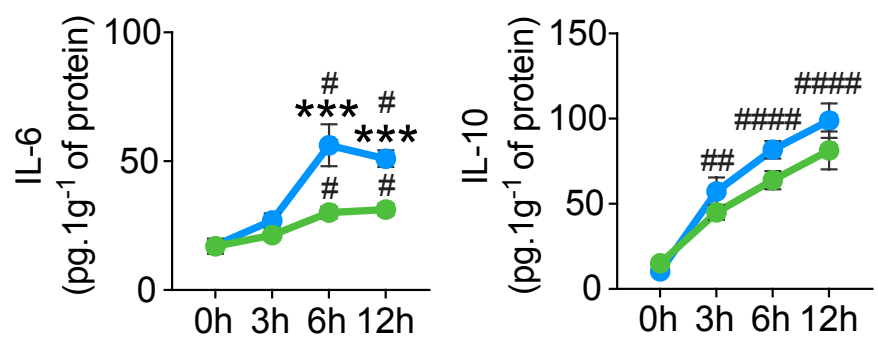

Figura 12: Animais deficientes para CCR2 apresentam menores níveis de IL-6 no rim. IL-6 e IL10 foram quantificadas por ELISA no tecido pulmonar de animais WT e KO submetidos a sepse moderada. Os resultados são representativos de dois experimentos realizados independentemente com 5 animais por grupo, e estão expressos como média \pm erro padrão da média (ANOVA com correção de Bonferroni, nível de significância: $p<0,05)$. ${ }^{*} p<0,05$ a $p=0,01 ;{ }^{* *} p<0,009$ a $p=0,001$; ${ }^{* * *}$ $p<0,0009$ a $p=0,0001 ;{ }^{* * *} p<0,0001$. * representa a comparação entre os animais CCR2 KO e WT. \# representa a comparação entre os grupos sham (0h) e indução de sepse (3h, 6h e 12h). 

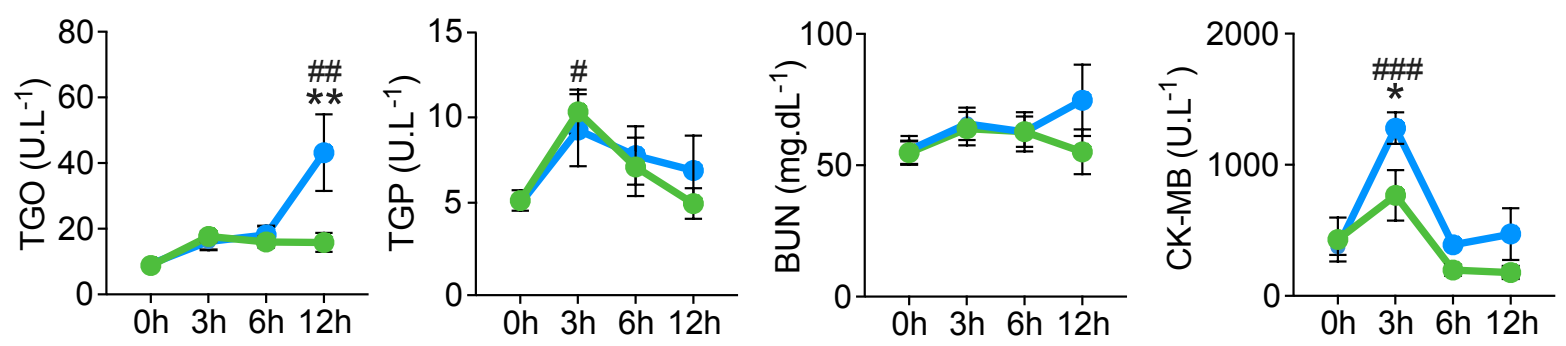

Figura 13: Animais deficientes para CCR2 apresentam menores níveis de marcadores de lesão de órgãos: TGO e CK-MB. Níveis de TGO, TGP, uréia (BUN) e CK-MB foram quantificados no plasma coletado de camundongos após a indução de sepse moderada. Os resultados são representativos de dois experimentos realizados independentemente com 5 animais por grupo, e estão expressos como média \pm erro padrão da média (ANOVA com correção de Bonferroni, nível de significância: $p<0,05)$. * $p<0,05$ a $p=0,01 ; * * \quad p<0,009$ a $p=0,001 ; * * * \quad p<0,0009$ a $p=0,0001$; **** $p<0,0001 .{ }^{*}$ representa a comparação entre os animais CCR2 KO e WT. \# representa a comparação entre os grupos sham (0h) e indução de sepse (3h, 6h e 12h).

\subsection{ANIMAIS DEFICIENTES PARA CCR2 QUE RECEBERAM MONÓCITOS INFLAMATÓRIOS APRESENTAM MENOR SOBREVIDA}

Como prova de conceito que a ausência de CCR2 desencadeia uma maior resistência dos animais à sepse devido a um menor recrutamento de monócitos inflamatórios para os órgãos, foram isolados monócitos inflamatórios da medula óssea de animais WT por sorting (Fig. 14C) e após $2 \mathrm{~h}$ da indução da sepse moderada ou grave essas células foram transferidas para camundongos deficientes para CCR2 para determinação da sobrevida.

Confirmando a nossa hipótese, observou-se que os animais $\mathrm{CCR}^{-/-}$que receberam monócitos inflamatórios apresentaram maior mortalidade em relação aos animais que não receberam e isso ocorreu independente da gravidade da sepse (Fig. 14A e Fig. 14B, respectivamente). Vale a pena ressaltar que os animais CCR2 ${ }^{-/-}$ que receberam monócitos inflamatórios apresentaram uma sobrevida muito semelhante aos animais WT, indicando que possivelmente é a ausência de monócitos inflamatórios, e não de qualquer outra célula, que confere resistência aos 
animais $\mathrm{CCR}^{-/-}$à sepse. Deste modo, podemos concluir que o monócito inflamatório possui papel deletério durante a sepse.
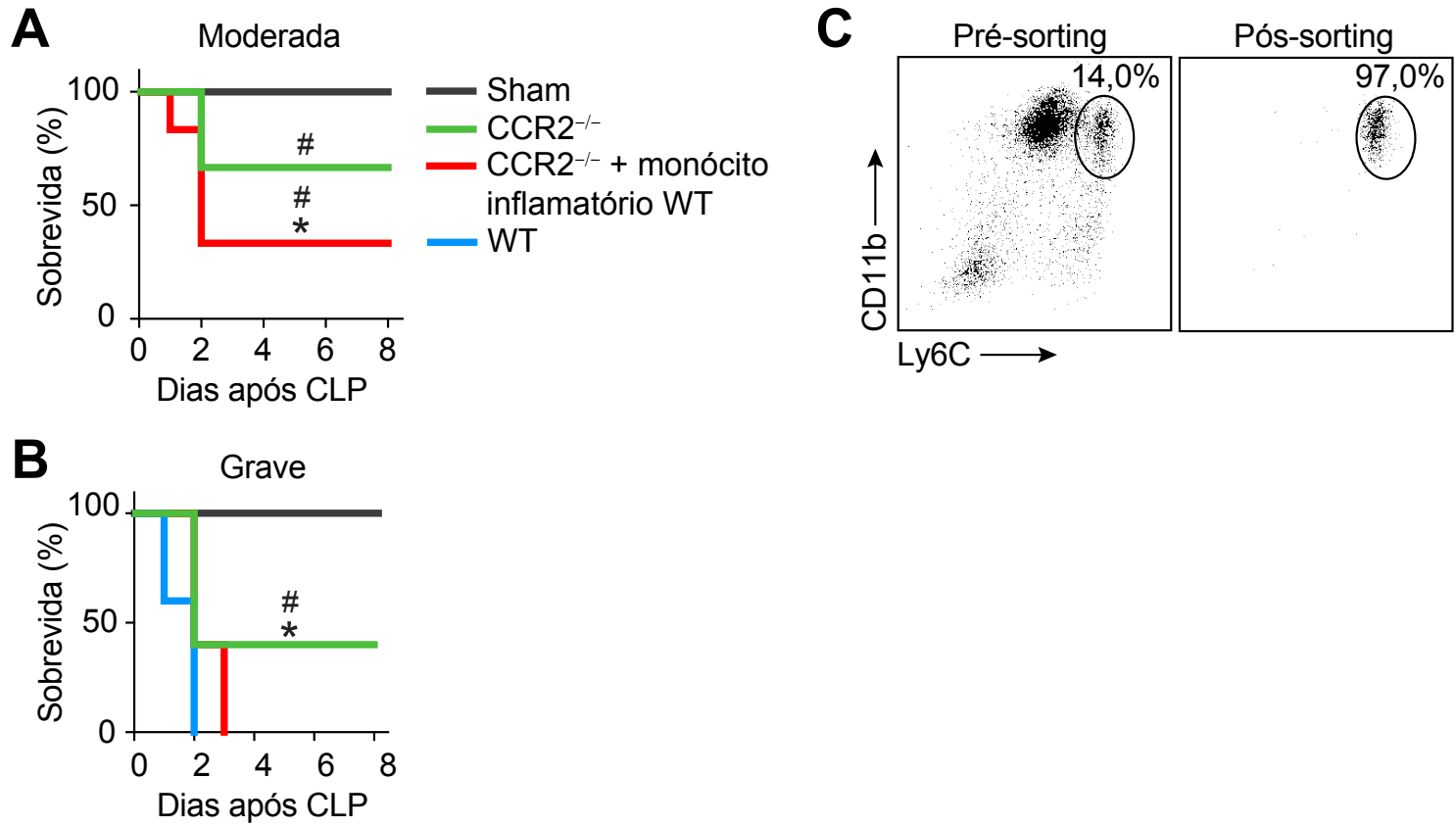

Figura 14: A transferência de monócitos inflamatórios para animais aumenta a suscetibilidade a sepse de animais deficientes para CCR2. Monócitos inflamatórios de animais WT foram sorteados $(C)$ da medula óssea e transferidos $\left(0,5 \times 10^{6}\right)$ para camundongos $\mathrm{CCR}^{-/-}$após $2 \mathrm{~h}$ da indução de sepse moderada (A) ou sepse grave (B). A sobrevida foi acompanhada por oito dias e comparada com camundongos deficientes para CCR2 que não receberam células. A avaliação da diferença na curva de sobrevida foi analisada utilizando o teste Mantel-Cox logrank (nível de significância: $p>0,05)$. * $p<0,05$ a $p=0,01$. * representa a comparação entre os grupos WT e KO. \# representa a comparação entre os grupos sham e WT. 


\section{Discussão}

A sepse é uma síndrome, na qual, o paciente apresenta lesões de órgãos com risco a vida, em decorrência de uma inflamação exacerbada desencadeada por uma infecção (SINGER et al., 2016). Os aspectos fisiopatológicos apresentados no contexto clínico dessa condição podem ser mimetizados experimentalmente através da metodologia de CLP (cecal ligation and puncture). Neste modelo a severidade da indução de sepse pode ser controlada através do número de perfurações no ceco dos animais e da quantidade do conteúdo fecal liberado. A sepse moderada apresenta uma taxa de mortalidade de aproximadamente 50\%; e a sepse considerada grave, uma taxa de mortalidade de 100\% (RITTIRSCH et al., 2009). Na sepse grave também se observa maiores quantidades de bactérias sistemicamente e no foco inflamatório, além de uma maior produção de quimiocinas e citocinas, menor infiltrado de neutrófilos na cavidade peritoneal, maior infiltrado dessas células em órgãos não infectados, e um aumento das lesões de órgãos (RUIZ et al., 2016; SINGLETON; WISCHMEYER, 2003; SÔNEGO et al., 2016).

Os monócitos inflamatórios são células importantes para o controle de microrganismos, pois possuem capacidade fagocítica, de produção de espécies reativas, além disso, produzem mediares inflamatórios, como por exemplo IL-6 e TNF, que ativam e recrutam outras populações celulares importantes na inflamação (KURIHARA et al., 1997; MUNOZ et al., 1991; PETERS et al., 2001; XIONG et al., 2016).

Estudos anteriores do nosso grupo de pesquisa descreveram uma redução na migração de neutrófilos para o foco infeccioso na sepse grave utilizando o modelo de CLP (ALVES-FILHO et al., 2008; SOUTO et al., 2011). No presente trabalho 
observou-se, um fenômeno semelhante para os monócitos inflamatórios, sugerindo que essa a diminuição da quantidade de monócitos inflamatórios estaria relacionada com o descontrole da infecção. Concomitante com esses achados observou-se um maior infiltrado de monócitos inflamatórios no pulmão. Deste modo, essas células podem estar contribuindo, através da sua atividade pró-inflamatória, com as lesões de órgãos já bem descritas na sepse grave. Fenômenos deletérios resultantes da migração dessas células são observados em outras doenças inflamatórias, como durante a patogênese da aterosclerose, em que monócitos Ly6C ${ }^{\text {high }}$ são recrutados para lesões ateroscleróticas, onde contribuem para o desenvolvimento de um processo inflamatório e consequente para a progressão da doença (SWIRSKI et al., 2007). Além disso, monócitos inflamatórios são recrutados para tumores, onde se diferenciam em macrófagos associados ao tumor, células que propiciam um microambiente favorável para a progressão tumoral (MADSEN et al., 2017; WOOLLARD; GEISSMANN, 2010).

Não há dúvida de que os monócitos inflamatórios são importantes no processo de resolução de infecções. No entanto, os resultados encontrados neste trabalho, demonstram um comportamento deletério dessas células na patogênese da sepse, isso por contribuírem com a exacerbação da inflamação sistêmica, e a migração dessas células para os órgãos rim e pulmão, estão relacionados com inflamação e aumento de lesões.

Corroborando nossa hipótese, um estudo que avaliou o perfil transcricional de monócitos totais em pacientes, durante o quadro séptico, demonstrou que essas células presentes na circulação apresentam um perfil pró-inflamatório (elevada

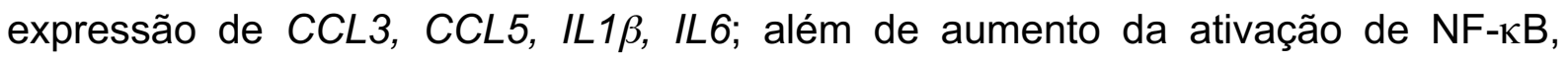
fagocitose e killing). No entanto, quando reestimuladas com LPS, essas células 
apresentam diminuição na expressão de CCL3, 4, 5; CXCL2, 11; IL1RA, IL1B, IL1 e TNF, de moléculas associadas a apresentação de antígenos (CD80, CD40 e HLA$D R$ ) e redução da ativação de NF-אB, e diminuição Por outro lado, a fagocitose e a atividade microbicida, bem como a atividade de remodelamento tecidual, permaneceram não alterados (DANIKAS et al., 2008; KIM et al., 2010; MANJUCK et al., 2000; SANTOS et al., 2016; SHALOVA et al., 2015).

Ainda, diversas abordagens que correlacionaram a quantidade de monócitos com a sobrevida ou a resposta séptica, dão suporte aos nossos resultados. GIAMARELLOS-BOURBOULIS e colaboradores demonstraram que o menor número de monócitos circulante, correlaciona-se com o aumento da sobrevida de pacientes, os quais apresentaram reduzida produção de TNF, IL-6 e IL-8 (GIAMARELLOS-BOURBOULIS et al., 2006). Outro trabalho demonstrou que animais deficientes para S100A9 apresentam excessiva expansão de monócitos inflamatórios no modelo de endotoxemia com LPS, e maior taxa de mortalidade. Porém, quando esses animais foram tratados com essa molécula, preveniu-se o aumento da quantidade de monócitos inflamatórios e observou-se menor taxa de mortalidade (HEINEMANN et al., 2017). Adicionalmente, também já foi descrito que a depleção de monócitos e macrófagos residentes em animais com sepse, utilizando Clodronato, acarretou na menor indução de IL-6, CXCL1, CXCL2 e CXCL5 sistemicamente e no pulmão (WANG et al., 2015). O tratamento com Intermedina melhorou o quadro de sepse induzida por CLP, na qual observou-se diminuição de lesões de órgãos, inflamação sistêmica e infiltrado de macrófagos no pulmão, células que apresentaram diminuição da expressão de CCR2 (XIAO et al., 2018).

A principal quimiocina que se liga no CCR2 é o CCL2, essa sinalização medeia a emigração de monócitos inflamatórios da medula óssea. Isso foi 
demonstrado, pois quando induzida uma inflamação em animais deficientes para CCR2, observou-se ativação dessas células na medula óssea, porém deficiência na sua emigração para a corrente sanguínea (SERBINA; PAMER, 2006; SHI; PAMER, 2011). Vários trabalhos no contexto de sepse, avaliaram a expressão ou produção de CCL2. Em pacientes sépticos a expressão de CCL2 se correlaciona positivamente com a bacteremia, destacando um descontrole do combate ao microrganismo no foco inflamatório (MOSEVOLL et al., 2018). Interessantemente, o aumento dos níveis dessa quimiocina também estão correlacionados com maior grau de lesões de órgãos em humanos (HOLUB et al., 2018), e seus níveis estão mais elevados em pacientes que posteriormente vêm a óbito (ZHU et al., 2017). Além disso, polimorfismos que são correlacionados com o aumento da expressão de CCL2, foram detectados em maior frequência em pacientes que apresentaram sepse grave (HE et al., 2017).

Estudos utilizando modelos experimentais corroboram com os achados em pacientes. Em modelo de CLP, em animais tratados com anti-CCL2 observou-se maior taxa de sobrevida e menor inflamação (MATSUKAWA et al., 2000; Y. et al., 2004), além de menor infiltrado celular, MPO, ROS e nitrito nos pulmões (ALVES et al., 2013; SPEYER et al., 2004). Adicionalmente, animais deficientes para CCR2 também apresentaram maior taxa de sobrevida (SOUTO et al., 2011) e uma menor migração de monócitos inflamatórios para o sistema nervoso central, foi associado a um menor dano cognitivo que é presente na sepse (ANDONEGUI et al., 2018).

Contudo, alguns trabalhos observaram resultados que diferem da conclusão obtida nos trabalhos discutidos anteriormente. Animais deficientes para CCR2 apresentaram maior lesão no rim após indução do CLP. Essa lesão foi restaurada quando se transferiu monócitos inflamatórios (CHOUSTERMAN et al., 2016). Além 
disso, observou-se maior quantidade de bactérias, maior inflamação e infiltrado de neutrófilos no pulmão de animais $\mathrm{CCR}^{-/-}$após a indução de sepse utilizando a infecção com S. pneumonia (WINTER et al., 2009; ZISMAN et al., 1997). Contudo, esse resultado diferente pode ser explicado pela utilização do modelo experimental diferente do CLP.

Animais deficientes para CCL2 apresentaram maior taxa de mortalidade quando induzida sepse por CLP. Interessantemente, esses animais não apresentaram diferença em relação ao controle de bactérias após $24 \mathrm{~h}$ quando comparados com animais WT. Isso, mesmo apresentando menor migração de células mononucleares o foco infeccioso. Observaram também que CCL2 é importante para a produção de IL-10, e não de TNF, por macrófagos peritoneais, e que isso correlaciona com a sobrevida observada (GOMES et al., 2006). Outro trabalho de Gomes e colaboradores, demonstraram que o tratamento com anti-CCL2 acarretou em menor controle da infecção no modelo de sepse por injeção de E. coli ou CLP. Isso devido a menor capacidade de eliminação de bactérias, devido a menor produção de NO por macrófagos do peritônio (GOMES et al., 2013). Podemos observar que a possível sinalização de CCL2 via o receptor CCR2 contribui com o processo de controle bacteriano por macrófagos peritoneais, porém em nossos resultados demonstramos que a produção de CCL2 não está diferente entre animais WT e deficientes para CCR2, e que os animais KO não apresentaram diferença em relação ao controle bacteriano. Em relação a produção de citocinas, observamos que os animais KO para CCR2 também apresentam menor produção de IL-10 como os CCL2 KO, porém o desfecho da indução de sepse é contrário.

Em conclusão, a maioria dos trabalhos discutidos em conjunto com nossos dados nos sugerem que monócitos inflamatórios são células que possuem papel 
deletério na patogênese da sepse, contribuindo com a exacerbação da inflamação sistêmica e lesões de órgãos. 


\section{Conclusão}

No presente trabalho demonstramos, em modelo experimental CLP, que o aumento da emigração de monócitos inflamatórios da medula óssea está relacionado com maior taxa de mortalidade dos animais, exacerbação da inflamação sistêmica e aumento de migração para órgãos (pulmão e rim). Nestes locais, essas células estão relacionadas com a indução de inflamação e aumento de lesões. Deste modo, conclui-se que os monócitos inflamatórios possuem um papel deletério na patogênese da sepse. 


\section{REFERÊNCIAS BIBLIOGRÁFICAS}

1. ALVES-FILHO, Jose C. et al. Regulation of chemokine receptor by Toll-like receptor 2 is critical to neutrophil migration and resistance to polymicrobial sepsis. [s. I.], p. 1-6, 2009.

2. ALVES-FILHO, José C. et al. Toll-like receptor 4 signaling leads to neutrophil migration impairment in polymicrobial sepsis. Critical care medicine, [s. I.], v. 34, n. 2, p. 461-70, 2006. Disponível em: <http://www.ncbi.nlm.nih.gov/pubmed/16424729>

3. ALVES-FILHO, José C. et al. The role of neutrophils in severe sepsis. Shock (Augusta, Ga.), [s. I.], v. 30 Suppl 1, p. 3-9, 2008. Disponível em: <http://www.ncbi.nlm.nih.gov/pubmed/18704017>

4. ALVES-FILHO, José C.; SPILLER, Fernando; CUNHA, Fernando Q. Neutrophil paralysis in sepsis. Shock (Augusta, Ga.), [s. I.], v. 34 Suppl 1, p. 15-21, 2010.2 Disponível em: <http://www.ncbi.nlm.nih.gov/pubmed/20714263>

5. ALVES-FILHO, José Carlos et al. Failure of neutrophil migration toward infectious focus in severe sepsis: a critical event for the outcome of this syndrome. Memórias do Instituto Oswaldo Cruz, [s. I.], v. 100, n. suppl 1, p. 223-226, $2005 . \quad$ Disponível em: <http://www.scielo.br/scielo.php?script=sci_arttext\&pid=S007402762005000900038\&lng=en\&tIng=en>

6. ALVES, Jackson Nogueira et al. Critical role for CCR2 and HMGB1 in induction of experimental endotoxic shock. Archives of Biochemistry and Biophysics, [s. I.], v. 537, n. 1, p. 72-81, 2013.

7. ANDONEGUI, Graciela et al. Targeting inflammatory monocytes in sepsisassociated encephalopathy and long-term cognitive impairment. JCI Insight, [s. I.], v. 3, n. 9, 2018. Disponível em: <https://insight.jci.org/articles/view/99364>

8. ANGUS, D. C. et al. Epidemiology of severe sepsis in the United States: analysis of incidence, outcome, and associated costs of care. Critical care medicine, [s. I.], v. 29, n. 7, p. 1303-10, 2001. Disponível em: <http://www.ncbi.nlm.nih.gov/pubmed/11445675>

9. ANGUS, Derek C.; VAN DER POLL, Tom. Severe Sepsis and Septic Shock. New England Journal of Medicine, [s. I.], v. 369, n. 9, p. 840-851, 2013. Disponível em: <http://www.nejm.org/doi/10.1056/NEJMra1208623>

10. AUFFRAY, Cedric et al. Monitoring of blood vessels and tissues by a population of monocytes with patrolling behavior. Science (New York, N.Y.), [s. I.], v. 317, n. 5838, p. 666-70, 2007. Disponível em: <http://www.ncbi.nlm.nih.gov/pubmed/17673663> 
11. AUFFRAY, Cedric; SIEWEKE, Michael H.; GEISSMANN, Frederic. Blood monocytes: development, heterogeneity, and relationship with dendritic cells. Annual review of immunology, [s. I.], v. 27, p. 669-92, 2009. Disponível em: <http://www.ncbi.nlm.nih.gov/pubmed/19132917>

12. BISWAS, Subhra K.; LOPEZ-COLLAZO, Eduardo. Endotoxin tolerance: new mechanisms, molecules and clinical significance. Trends in Immunology, [s. I.], v. 30, n. 10, p. 475-487, 2009. Disponível em: <http://linkinghub.elsevier.com/retrieve/pii/S1471490609001549>

13. BONE, R. C.; GRODZIN, C. J.; BALK, R. A. Sepsis: a new hypothesis for pathogenesis of the disease process. Chest, [s. I.], v. 112, n. 1, p. 235-43, 1997. Disponível em: <http://www.ncbi.nlm.nih.gov/pubmed/9228382>

14. CERRA, F. B. The systemic septic response: multiple systems organ failure. Critical care clinics, [s. I.], v. 1, n. 3, p. 591-607, 1985. Disponível em: <http://www.ncbi.nlm.nih.gov/pubmed/3916795>

15. CHAN, James K. et al. Alarmins: awaiting a clinical response. Journal of Clinical Investigation, [s. I.], v. 122, n. 8, p. 2711-2719, 2012. Disponível em: <http://www.jci.org/articles/view/62423>

16. CHOUSTERMAN, Benjamin G. et al. Ly6Chigh Monocytes Protect against Kidney Damage during Sepsis via a CX3CR1-Dependent Adhesion Mechanism. Journal of the American Society of Nephrology: JASN, [s. I.], v. $27, \quad$ n. $3, \quad$ p. 792-803, 2016. Disponível em: <http://www.ncbi.nlm.nih.gov/pubmed/26160897>

17. CROS, Jérôme et al. Human CD14dim monocytes patrol and sense nucleic acids and viruses via TLR7 and TLR8 receptors. Immunity, [s. I.], v. 33, n. 3, p. 2010. 375-86, Disponível em: <http://www.ncbi.nlm.nih.gov/pubmed/20832340>

18. DANIKAS, D. D. et al. Prognostic value of phagocytic activity of neutrophils and monocytes in sepsis. Correlation to CD64 and CD14 antigen expression. Clinical \& Experimental Immunology, [s. I.], v. 154, n. 1, p. 87-97, 2008. Disponível em: <http://doi.wiley.com/10.1111/j.1365-2249.2008.03737.x>

19. DEUTSCHMAN, Clifford S.; TRACEY, Kevin J. Sepsis: Current Dogma and New Perspectives. Immunity, [s. I.], v. 40, n. 4, p. 463-475, 2014. Disponível em: <https://linkinghub.elsevier.com/retrieve/pii/S1074761314001150>

20. DINARELLO, C. A. Proinflammatory and anti-inflammatory cytokines as mediators in the pathogenesis of septic shock. Chest, [s. I.], v. 112, n. 6 Suppl, p. 321S-329S, 1997. Disponível em: <http://www.ncbi.nlm.nih.gov/pubmed/9400897>

21. DUNAY, Ildiko $\mathrm{R}$. et al. Gr1(+) inflammatory monocytes are required for mucosal resistance to the pathogen Toxoplasma gondii. Immunity, [s. I.], v. 29, n. 2, p. 306-17, 2008. Disponível em: <http://www.ncbi.nlm.nih.gov/pubmed/18691912> 
22. ESCOLL, Pedro et al. Rapid up-regulation of IRAK-M expression following a second endotoxin challenge in human monocytes and in monocytes isolated from septic patients. Biochemical and Biophysical Research Communications, [s. I.], v. 311, n. 2, p. 465-472, 2003. Disponível em: <http://linkinghub.elsevier.com/retrieve/pii/S0006291X03020862>

23. FLEISCHMANN, Carolin et al. Assessment of global incidence and mortality of hospital-treated sepsis current estimates and limitations. American Journal of Respiratory and Critical Care Medicine, [s. I.], v. 193, n. 3, p. 259-272, 2016.

24. FUNK, Duane J.; PARRILLO, Joseph E.; KUMAR, Anand. Sepsis and Septic Shock: A History. Critical Care Clinics, [s. I.], v. 25, n. 1, p. 83-101, 2009. Disponível <http://linkinghub.elsevier.com/retrieve/pii/S0749070408000808>

em:

25. GEISSMANN, Frederic; JUNG, Steffen; LITTMAN, Dan R. Blood monocytes consist of two principal subsets with distinct migratory properties. Immunity, [s. I.], v. 19, n. 1, p. 71-82, 2003. Disponível em: <http://www.ncbi.nlm.nih.gov/pubmed/12871640>

26. GIAMARELLOS-BOURBOULIS, Evangelos J. et al. Early apoptosis of blood monocytes in the septic host: is it a mechanism of protection in the event of septic shock? Critical care (London, England), [s. I.], v. 10, n. 3, p. R76, 2006. Disponível em: <http://www.ncbi.nlm.nih.gov/pubmed/16696867>

27. GOMES, Rachel $\mathrm{N}$. et al. Increased susceptibility to septic and endotoxic shock in monocyte chemoattractant protein 1/CC chemokine ligand 2-deficient mice correlates with reduced interleukin 10 and enhanced macrophage migration inhibitory factor production. Shock, [s. I.], v. 26, n. 5, p. 457-463, 2006.

28. GOMES, Rachel N. et al. Bacterial clearance in septic mice is modulated by MCP-1/CCL2 and nitric oxide. Shock, [s. I.], v. 39, n. 1, p. 63-69, 2013.

29. HE, Junbing et al. Association study of MCP-1 promoter polymorphisms with the susceptibility and progression of sepsis. PLoS ONE, [s. I.], v. 12, n. 5, p. 1-14, 2017.

30. HEINEMANN, Anna S. et al. In neonates S100A8/S100A9 alarmins prevent the expansion of a specific inflammatory monocyte population promoting septic shock. FASEB Journal, [s. I.], v. 31, n. 3, p. 1153-1164, 2017.

31. HOLUB, Michal et al. Selected Biomarkers Correlate with the Origin and Severity of Sepsis. Mediators of inflammation, [s. I.], v. 2018, p. 7028267, 2018.

32. HOTCHKISS, Richard S. et al. Sepsis and septic shock. Nature Reviews Disease Primers, [s. I.], v. 2, n. June, p. 16045, 2016. Disponível em: <http://www.nature.com/articles/nrdp201645>

33. KIM, Oh et al. Differential down-regulation of HLA-DR on monocyte 
subpopulations during systemic inflammation. Critical Care, [s. I.], v. 14, n. 2, p. R61, 2010. Disponível em: <http://ccforum.biomedcentral.com/articles/10.1186/cc8959>

34. KUBES, Paul. The complexities of leukocyte recruitment. Seminars in immunology, [s. I.], v. 14, n. 2, p. 65-72, 2002. Disponível em: <http://www.ncbi.nlm.nih.gov/pubmed/11978078>

35. KURIHARA, T. et al. Defects in macrophage recruitment and host defense in mice lacking the CCR2 chemokine receptor. The Journal of experimental medicine, [s. I.], v. 186, n. 10, p. 1757-62, 1997. Disponível em: <http://www.ncbi.nlm.nih.gov/pubmed/9362535>

36. MACHADO, Flavia R. et al. The epidemiology of sepsis in Brazilian intensive care units (the Sepsis PREvalence Assessment Database, SPREAD): an observational study. The Lancet Infectious Diseases, [s. I.], v. 17, n. 11, p. 1180-1189, 2017. Disponível em: <http://linkinghub.elsevier.com/retrieve/pii/S1473309917303225>

37. MADSEN, Daniel Hargbøl et al. Tumor-Associated Macrophages Derived from Circulating Inflammatory Monocytes Degrade Collagen through Cellular Uptake. Cell Reports, [s. I.], v. 21, n. 13, p. 3662-3671, 2017. Disponível em: <https://linkinghub.elsevier.com/retrieve/pii/S2211124717318077>

38. MANJUCK, J. et al. Decreased response to recall antigens is associated with depressed costimulatory receptor expression in septic critically ill patients. The Journal of laboratory and clinical medicine, [s. I.], v. 135, n. 2, p. 153-60, 2000. Disponível em: <http://www.ncbi.nlm.nih.gov/pubmed/10695660>

39. MARTIN, Greg S. et al. The Epidemiology of Sepsis in the United States from 1979 through 2000. New England Journal of Medicine, [s. I.], v. 348, n. 16, p. 2003. 1546-1554, Disponível em: <http://www.nejm.org/doi/abs/10.1056/NEJMoa022139>

40. MATSUKAWA, Akihiro et al. Endogenous MCP-1 influences systemic cytokine balance in a murine model of acute septic peritonitis. Experimental and Molecular Pathology, [s. I.], v. 68, n. 2, p. 77-84, 2000.

41. MEDZHITOV, Ruslan. Recognition of microorganisms and activation of the immune response. Nature, [s. I.], v. 449, n. 7164, p. 819-26, 2007. Disponível em: <http://www.ncbi.nlm.nih.gov/pubmed/17943118>

42. MEDZHITOV, Ruslan; JANEWAY, Charles. Innate Immunity. New England Journal of Medicine, [s. I.], v. 343, n. 5, p. 338-344, 2000. Disponível em: <http://www.nejm.org/doi/10.1056/NEJM200008033430506>

43. MOSEVOLL, Knut Anders et al. Inflammatory mediator profiles differ in sepsis patients with and without bacteremia. Frontiers in Immunology, [s. I.], v. 9, n. APR, 2018.

44. MUNOZ, C. et al. Dysregulation of in vitro cytokine production by monocytes during sepsis. The Journal of clinical investigation, [s. I.], v. 88, n. 5, p. 
1747-54,

1991.

Disponível

em:

<http://www.ncbi.nlm.nih.gov/pubmed/1939659>

45. OPAL, Steven M. et al. Systemic Host Responses in Severe Sepsis Analyzed by Causative Microorganism and Treatment Effects of Drotrecogin Alfa (Activated). Clinical Infectious Diseases, [s. I.], v. 37, n. 1, p. 50-58, 2003. Disponível em: <https://academic.oup.com/cid/article/37/1/50/474337>

46. PACHOT, Alexandre et al. Systemic transcriptional analysis in survivor and non-survivor septic shock patients: A preliminary study. Immunology Letters, [s. I.], v. 106, n. 1, p. 63-71, 2006. Disponível em: <http://linkinghub.elsevier.com/retrieve/pii/S0165247806001210>

47. PETERS, W. et al. Chemokine receptor 2 serves an early and essential role in resistance to Mycobacterium tuberculosis. Proceedings of the National Academy of Sciences of the United States of America, [s. I.], v. 98, n. 14, p. 7958-63, 2001. Disponível em: <http://www.ncbi.nlm.nih.gov/pubmed/11438742>

48. RANIERI, V. Marco et al. Drotrecogin Alfa (Activated) in Adults with Septic Shock. New England Journal of Medicine, [s. I.], v. 366, n. 22, p. 20552064, $2012 . \quad$ Disponível em: <http://www.nejm.org/doi/abs/10.1056/NEJMoa1202290>

49. REINHART, Konrad et al. Recognizing Sepsis as a Global Health Priority - A WHO Resolution. New England Journal of Medicine, [s. I.], v. 377, n. 5, p. 414-417, $2017 . \quad$ Disponível em: <http://www.nejm.org/doi/10.1056/NEJMp1707170>

50. RIOS-SANTOS, Fabrício et al. Down-regulation of CXCR2 on Neutrophils in Severe Sepsis Is Mediated by Inducible Nitric Oxide Synthase-derived Nitric Oxide. American Journal of Respiratory and Critical Care Medicine, [s. I.], v. 175, n. 5, p. 490-497, 2007. Disponível em: <http://www.atsjournals.org/doi/abs/10.1164/rccm.200601-1030C>

51. RITTIRSCH, Daniel et al. Immunodesign of experimental sepsis by cecal ligation and puncture. Nature Protocols, [s. I.], v. 4, n. 1, p. 31-36, 2009. Disponível em: <http://www.nature.com/articles/nprot.2008.214>

52. RUIZ, Stéphanie et al. Sepsis modeling in mice: ligation length is a major severity factor in cecal ligation and puncture. Intensive care medicine experimental, [s. I.], v. 4, n. 1, p. 22, 2016. Disponível em: <http://www.ncbi.nlm.nih.gov/pubmed/27430881>

53. SANTOS, Sidnéia $S$. et al. Modulation of monocytes in septic patients: preserved phagocytic activity, increased ROS and NO generation, and decreased production of inflammatory cytokines. Intensive Care Medicine Experimental, [s. I.], v. 4, n. 1, p. 5, 2016. Disponível em: <http://www.icmexperimental.com/content/4/1/5>

54. SERBINA, Natalya V. et al. Monocyte-Mediated Defense Against Microbial Pathogens. Annual Review of Immunology, [s. I.], v. 26, n. 1, p. 421-452, 
2008.

<http://www.annualreviews.org/doi/10.1146/annurev.immunol.26.021607.0903 26>

55. SERBINA, Natalya V; PAMER, Eric G. Monocyte emigration from bone marrow during bacterial infection requires signals mediated by chemokine receptor CCR2. Nature Immunology, [s. I.], v. 7, n. 3, p. 311-317, 2006. Disponível em: <http://www.nature.com/articles/ni1309>

56. SHALOVA, Irina $\mathrm{N}$. et al. Human monocytes undergo functional reprogramming during sepsis mediated by hypoxia-inducible factor-1?? Immunity, [s. I.], v. 42, n. 3, p. 484-498, 2015.

57. SHI, Chao et al. Bone Marrow Mesenchymal Stem and Progenitor Cells Induce Monocyte Emigration in Response to Circulating Toll-like Receptor Ligands. Immunity, [s. I.], v. 34, n. 4, p. 590-601, 2011. Disponível em: <http://linkinghub.elsevier.com/retrieve/pii/S1074761311000744>

58. SHI, Chao; PAMER, Eric G. Monocyte recruitment during infection and inflammation. Nature Reviews Immunology, [s. I.], v. 11, n. 11, p. 762-774, 2011. Disponível em: <http://www.nature.com/doifinder/10.1038/nri3070>

59. SINGER, Mervyn et al. The Third International Consensus Definitions for Sepsis and Septic Shock (Sepsis-3). JAMA, [s. I.], v. 315, n. 8, p. 801-10, 2016. Disponível em: <http://www.ncbi.nlm.nih.gov/pubmed/26903338>

60. SINGLETON, K. D.; WISCHMEYER, P. E. Distance of cecum ligated influences mortality, tumor necrosis factor-alpha and interleukin-6 expression following cecal ligation and puncture in the rat. European surgical research. Europaische chirurgische Forschung. Recherches chirurgicales europeennes, [s. I.], v. 35, n. 6, p. 486-91, 2003. Disponível em: <http://www.ncbi.nlm.nih.gov/pubmed/14593232>

61. SOGAYAR, Ana M. C. et al. A multicentre, prospective study to evaluate costs of septic patients in Brazilian intensive care units. PharmacoEconomics, [s. I.], v. 26, n. 5, p. 425-34, 2008. Disponível em: <http://www.ncbi.nlm.nih.gov/pubmed/18429658>

62. SÔNEGO, Fabiane et al. Paradoxical Roles of the Neutrophil in Sepsis: Protective and Deleterious. Frontiers in Immunology, [s. I.], v. 7, 2016. Disponível <http://journal.frontiersin.org/Article/10.3389/fimmu.2016.00155/abstract>

63. SOUTO, Fabricio $O$. et al. Essential role of CCR2 in neutrophil tissue infiltration and multiple organ dysfunction in sepsis. American journal of respiratory and critical care medicine, [s. I.], v. 183, n. 2, p. 234-42, 2011. Disponível em: <http://www.ncbi.nlm.nih.gov/pubmed/20732989>

64. SPEYER, Cecilia L. et al. Novel chemokine responsiveness and mobilization of neutrophils during sepsis. American Journal of Pathology, [s. I.], v. 165, n. 6, p. 2187-2196, 2004. 
65. STEARNS-KUROSAWA, Deborah J. et al. The Pathogenesis of Sepsis. Annual Review of Pathology: Mechanisms of Disease, [s. I.], v. 6, n. 1, p. 19-48, 2011.

Disponível

em:

<http://www.annualreviews.org/doi/10.1146/annurev-pathol-011110-130327>

66. SWIRSKI, Filip K. et al. Ly-6Chi monocytes dominate hypercholesterolemiaassociated monocytosis and give rise to macrophages in atheromata. The Journal of clinical investigation, [s. I.], v. 117, n. 1, p. 195-205, 2007. Disponível em: <http://www.ncbi.nlm.nih.gov/pubmed/17200719>

67. TRAYNOR, Tim R. et al. Differential roles of CC chemokine ligand $2 /$ monocyte chemotactic protein-1 and CCR2 in the development of T1 immunity. Journal of immunology (Baltimore, Md.: 1950), [s. I.], v. 168, n. 9, p. 4659-66, 2002. Disponível em: <http://www.ncbi.nlm.nih.gov/pubmed/11971015>

68. TSOU, Chia-Lin et al. Critical roles for CCR2 and MCP-3 in monocyte mobilization from bone marrow and recruitment to inflammatory sites. The Journal of clinical investigation, [s. I.], v. 117, n. 4, p. 902-9, 2007. Disponível em: <http://www.ncbi.nlm.nih.gov/pubmed/17364026>

69. VAN DER POLL, Tom et al. The immunopathology of sepsis and potential therapeutic targets. Nature Reviews Immunology, [s. I.], v. 17, n. 7, p. 407-

420, 2017.
<http://www.nature.com/doifinder/10.1038/nri.2017.36>

70. VINCENT, J. L. et al. Use of the SOFA score to assess the incidence of organ dysfunction/failure in intensive care units: results of a multicenter, prospective study. Working group on "sepsis-related problems" of the European Society of Intensive Care Medicine. Critical care medicine, [s. I.], v. 26, n. 11, p. 1793800, 1998. Disponível em: <http://www.ncbi.nlm.nih.gov/pubmed/9824069>

71. VINCENT, Jean-Louis et al. International study of the prevalence and outcomes of infection in intensive care units. JAMA, [s. I.], v. 302, n. 21, p. 2323-9, 2009. Disponível em: <http://www.ncbi.nlm.nih.gov/pubmed/19952319>

72. WANG, Yongzhi et al. Monocytes regulate systemic coagulation and inflammation in abdominal sepsis. American Journal of Physiology - Heart and Circulatory Physiology, [s. I.], v. 308, n. 5, p. H540-H547, 2015. Disponível em: <http://ajpheart.physiology.org/lookup/doi/10.1152/ajpheart.00336.2014>

73. WEBER, C. et al. Specialized roles of the chemokine receptors CCR1 and CCR5 in the recruitment of monocytes and $\mathrm{T}(\mathrm{H}) 1$-like/CD45RO $(+) \mathrm{T}$ cells. Blood, [s. I.], v. 97, n. 4, p. 1144-6, 2001. Disponível em: <http://www.ncbi.nlm.nih.gov/pubmed/11159551>

74. WINTER, C. et al. Important Role for CC Chemokine Ligand 2-Dependent Lung Mononuclear Phagocyte Recruitment to Inhibit Sepsis in Mice Infected with Streptococcus pneumoniae. The Journal of Immunology, [s. I.], v. 182, n. $8, \quad$ p. 4931-4937, 2009. Disponível em: 
<http://www.jimmunol.org/cgi/doi/10.4049/jimmunol.0804096>

75. WOOLLARD, Kevin J.; GEISSMANN, Frederic. Monocytes in atherosclerosis: subsets and functions. Nature reviews. Cardiology, [s. I.], v. 7, n. 2, p. 7786, 2010. Disponível em: <http://www.ncbi.nlm.nih.gov/pubmed/20065951>

76. XIAO, Fei et al. Intermedin protects against sepsis by concurrently reestablishing the endothelial barrier and alleviating inflammatory responses. Nature Communications, [s. I.], v. 9, n. 1, p. 1-15, 2018.

77. XIONG, Huizhong et al. Innate Lymphocyte/Ly6C(hi) Monocyte Crosstalk Promotes Klebsiella Pneumoniae Clearance. Cell, [s. I.], v. 165, n. 3, p. 67989, 2016. Disponível em: <http://www.ncbi.nlm.nih.gov/pubmed/27040495>

78. Y., Tsuda et al. CCL2, a product of mice early after systemic inflammatory response syndrome (SIRS), induces alternatively activated macrophages capable of impairing antibacterial resistance of SIRS mice. Journal of Leukocyte Biology, [s. I.], v. 76, n. 2, p. 368-373, 2004. Disponível em: $<$ http://ovidsp.ovid.com/ovidweb.cgi?T=JS\&PAGE=reference\&D=emed9\&NE WS=N\&AN=39006950>

79. ZHU, Tingting et al. Plasma Monocyte Chemoattractant Protein 1 as a Predictive Marker for Sepsis Prognosis: A Prospective Cohort Study. The Tohoku Journal of Experimental Medicine, [s. I.], v. 241, n. 2, p. 139-147, $2017 . \quad$ Disponível em: <https://www.jstage.jst.go.jp/article/tjem/241/2/241_139/_article>

80. ZIEGLER-HEITBROCK, Loems. The CD14+ CD16+ blood monocytes: their role in infection and inflammation. Journal of leukocyte biology, [s. I.], v. 81, n. 3, p. 584-92, 2007. Disponível em: <http://www.ncbi.nlm.nih.gov/pubmed/17135573>

81. ZIEGLER-HEITBROCK, Loems et al. Nomenclature of monocytes and dendritic cells in blood. Blood, [s. I.], v. 116, n. 16, p. e74-80, 2010. Disponível em: <http://www.ncbi.nlm.nih.gov/pubmed/20628149>

82. ZISMAN, David A. et al. MCP-1 protects mice in lethal endotoxemia. Journal of Clinical Investigation, [s. I.], v. 99, n. 12, p. 2832-2836, 1997. 


\section{APÊNDICE}

\section{APÊNDICE A - Comitê de ética no uso de animais para experimentação}
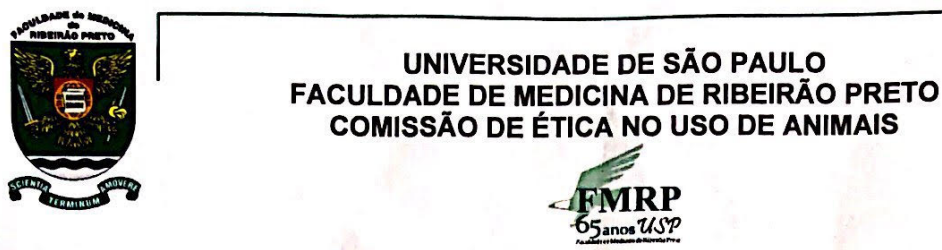

Certificamos que o Protocolo intitulado "Participação dos monócitos inflamatórios na fisiopatologia da sepse: envolvimento do receptor CCR5 no recrutamento para o foco infecioso e ativação de mecanismos microbicidas", registrado com o número 080/2018, sob a responsabilidade do Prof. Dr. Fernando de Queiroz Cunha, envolvendo a produção, manutenção ou utilização de animais pertencentes ao filo Chordata, subfilo Vertebrata (exceto humanos) para fins de pesquisa científica, encontra-se de acordo com os preceitos da Lei $n^{\circ} 11.794$ de 8 de outubro de 2008, do Decreto $n^{\circ} 6.899$ de 15 de julho de 2009 e com as normas editadas pelo Conselho Nacional de Controle de Experimentação Animal (CONCEA), e foi APROVADo pela Comissão de Ética no Uso de Animais da Faculdade de Medicina de Ribeirão Preto da Universidade de São Paulo em reunião de 25 de junho de 2018.

Este Protocolo prevê a utilização de 180 camundongos C57B1/6 machos pesando $20 \mathrm{~g}$ oriundos do Serviço de Biotério da Prefeitura do Campus de Ribeirão Preto da Universidade de São Paulo e 18 camundongos CCR-5 KO machos pesando $20 \mathrm{~g}, 18$ camundongos CCR-5 KO machos pesando $20 \mathrm{~g}, 18$ camundongos TLR-4 KO machos pesando 20g, 18 camundongos TLR2 KO machos pesando 20g, 18 camundongos Nod-1 KO machos pesando 20g, 18 camundongos Nod-2 KO machos pesando 20g, 18 camundongos TNFR KO machos pesando $20 \mathrm{~g}$, 18 camundongos IL-6 KO machos pesando $20 \mathrm{~g}$, 18 camundongos IL$1 \mathrm{R}$ KO machos pesando $20 \mathrm{~g}$ e 18 camundongos IFN? KO machos pesando $20 \mathrm{~g}$, oriundos do Centro de Criação de Camundongos Especiais da Faculdade de Medicina de Ribeirão Preto da Universidade de São Paulo. Vigência da autorização: 25/06/2018 a 26/06/2019. 


\section{UNIVERSIDADE DE SĀO PAULO \\ FACULDADE DE MEDICINA DE RIBEIRÃO PRETO COMISSÃO DE ÉTICA NO USO DE ANIMAIS

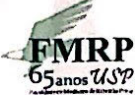

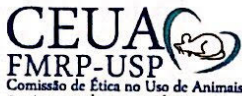

We certify that the Protocol $n^{\circ} \mathbf{0 8 0 / 2 0 1 8}$, entitled "The role of the inflammatory monocytes in the pathophysiology of sepsis: the involvement of the CCR5 on the recruitment and activation of the microbicide mechanisms of these cells", is in accordance with the Ethical Principles in Animal Research adopted by the National Council for the Control of Animal Experimentation (CONCEA) and was approved by the Local Animal Ethical Committee from Ribeirão Preto Medical School of the University of São Paulo in 06/25/2018. This protocol involves the production, maintenance or use of animals from phylum Chordata, subphylum Vertebrata (except humans) for research purposes, and includes the use of 180 male C57Bl $/ 6$ mice weighing $20 \mathrm{~g}$ from the Central Animal House of Ribeirao Preto Medical School and 18 male CCR-5 KO mice weighing $20 \mathrm{~g}, 18$ male TLR-4 KO mice weighing $20 \mathrm{~g}, 18$ male TLR2 KO mice weighing 20g, 18 male Nod-1 KO mice weighing $20 \mathrm{~g}, 18$ male Nod-2 $\mathrm{KO}$ mice weighing $20 \mathrm{~g}, 18$ male TNFR KO mice weighing $20 \mathrm{~g}, 18$ male IL-6 KO mice weighing $20 \mathrm{~g}$, 18 male IL-1R KO mice weighing $20 \mathrm{~g}$ and 18 male IFN? KO mice weighing $20 \mathrm{~g}$, from the Breeding Center of Special Mice of Ribeirao Preto Medical School, University of São Paulo. This certificate is valid until 06/26/2019.

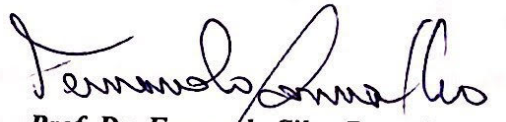

Prof. Dr. Fernando Silva Ramalho Coordenador da/CEUA-FMRP - USP 